\title{
Instability Mechanism of Extraction Structure in Whole Life Cycle in Block Caving Mine
}

\author{
Zhi-Yuan Xia $\mathbb{D}^{1,2,3}$ Zhuo-Ying Tan $\mathbb{D}^{1,2,3}$ and Lei Zhang $\mathbb{D}^{4}$ \\ ${ }^{1}$ School of Civil \& Resource Engineering, University of Science and Technology Beijing, Beijing 100083, China \\ ${ }^{2}$ State Key Laboratory of High-Efficient Mining and Safety of Metal Mine, Ministry of Education, University of Science and \\ Technology Beijing, Beijing 100083, China \\ ${ }^{3}$ Beijing Key Laboratory of Urban Underground Space Engineering, University of Science and Technology Beijing, \\ Beijing 100083, China \\ ${ }^{4}$ China Xinxing Mining and Chemical Co., Ltd., Beijing 100083, China
}

Correspondence should be addressed to Zhi-Yuan Xia; zhiyuanxia1991@126.com

Received 4 March 2021; Revised 19 March 2021; Accepted 27 March 2021; Published 15 April 2021

Academic Editor: Yi Xue

Copyright ( $) 2021$ Zhi-Yuan Xia et al. This is an open access article distributed under the Creative Commons Attribution License, which permits unrestricted use, distribution, and reproduction in any medium, provided the original work is properly cited.

\begin{abstract}
In the whole life cycle of the extraction structure in block caving mine from the beginning of roadways excavation to the end of ore drawing, there are many factors affecting the stability of the extraction structure. The investigation in the mine site shows that the extraction structure often presents the law of repeated instability. In order to reveal the mechanism of repeated instability of the extraction structure, the whole life cycle of extraction structure can be divided into three stages, namely, the formation stage of extraction structure, the undercutting stage without initial caving, and the ore caving and drawing stage. The three-dimensional finite difference software FLAC ${ }^{3 \mathrm{D}}$ was used to establish the numerical model of the extraction structure in the whole life cycle in the block caving method. The process of ore caving and ore drawing was replaced by manual excavation of the caving area above the undercut space and applying stress on the major apex. The stress and displacement evolution laws of the extraction structure in three stages of the whole life cycle were studied and compared with the instability characteristics of the extraction structure on mine site. The whole life cycle instability mechanism of the extraction structure in Tongkuangyu mine is revealed; the research results show that the extraction structure near the advancing undercut front is prone to producing compressive stress concentration under the action of the surrounding rock stress arch in the stope; if the rock mass shear failure condition is reached, the instability of the extraction structure occurs. The extraction structure near the advancing undercut front is gradually transferred to the area under the undercut space with undercut increase, and the tensile stress concentration gradually appears in the sidewall of ore loading roadway and the tip of major apex; if the tensile strength of the rock mass in the extraction structure is exceeded, the instability occurs again. It is helpful to reduce the probability of the instability of the extraction structure to promote the overburden ore caving as soon as possible after the undercutting begins.
\end{abstract}

\section{Introduction}

With the increasingly fierce market competition in recent years, the use of efficient mining methods and large-scale automatic equipment has become a trend in mining industry. Block caving is a low-cost, high efficiency, and largescale mining method; block caving mining is the preferred method for mining deep mineral resources because of its small amount of rock drilling and large production capacity [1-3]. The extraction structure of the block caving method is the general term of a series of roadways and chambers used for ore drawing between the undercut level and the production level $[4,5]$. The extraction structure undertakes the task of ore drawing. Once the extraction structure is damaged, the caved ores cannot be transported from the production level. Therefore, the stability of the extraction structure is very important, which is one of the key factors for the successful application of the block caving method. Due to the long service life of the extraction structure in the block caving mine and many factors affecting the 


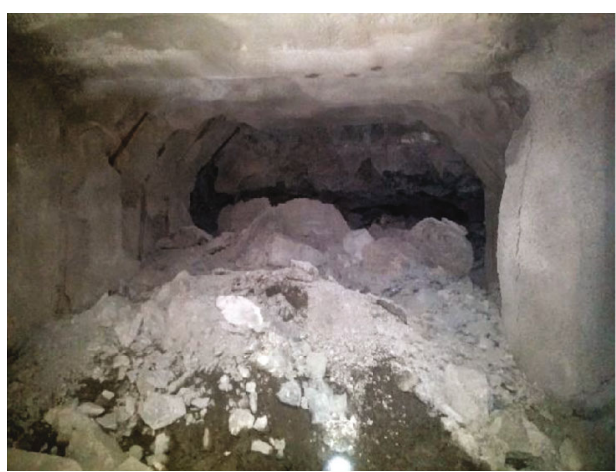

(a)

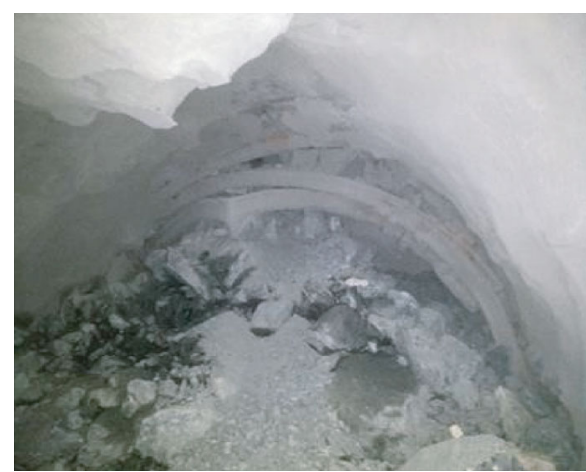

(b)

FIGURE 1: Instability of extraction structure in Tongkuangyu mine: (a) collapse of the ore loading roadway and (b) bending of steel arch frame in ore drawing roadway.

stability, the maintenance of the extraction structure is difficult and the risk of instability is high.

Many experts have studied the instability reasons of the extraction structure during the process of block caving mining. Trueman et al. [6-8] studied the effect of undercut mode, horizontal stress, and other factors on the extraction structure of block caving method by using theoretical analysis, numerical simulation, and other methods, and related control measures was proposed. Rojas et al. $[9,10]$ monitored the stress and microseismic events of the production roadways to explore reasons of the instability of the extraction structure during the ore caving stage. Pierce et al. [11-13] studied the force of ore bulk on the extraction structure in the ore drawing stage, and the research results showed that unbalanced ore drawing was not conducive to the stability of the extraction structure, and the maximum vertical stress of the ore drawing roadway can reach 12 times of the vertical stress at the bottom of the ore bulk. Castro et al. $[14,15]$ used laboratory physical experiment to explore the vertical stress of extraction structure during the ore drawing stage, and the research conclusions presented that the vertical stress was mainly influenced by the area of ore drawing area and the distance between the monitoring point and the ore drawing advancing front.

In the whole life cycle of the extraction structure of the block caving mine from the beginning of roadways excavation to the end of ore drawing, there are many factors affecting its stability. Under the condition of large horizontal in situ stress, it is found that the extraction structure often presents the law of repeated instability. Previous studies have not really revealed the repeated instability mechanism of the extraction structure in the whole life cycle in the block caving method. Xia et al. [16-18] revealed the reasons for the repeated instability mechanism of the extraction structure during the process of undercutting but did not take into account the influence of the ore caving stage. In order to reveal the mechanism of repeated instability of the extraction structure, the whole life cycle of the extraction structure can be divided into three stages, namely, the formation stage of extraction structure, the undercutting stage without initial caving, and the ore caving and drawing stage. Based on the engineering background of Tongkuangyu mine, a typical block caving mine in China, the evolution characteristics of stress and displacement of the extraction structure in the whole life cycle of block caving were simulated by using three-dimensional finite difference software $\mathrm{FLAC}^{3 \mathrm{D}}$, and the simulation results were compared with the instability characteristics of the extraction structure in mine site. The instability mechanism of the extraction structure in the whole life cycle is revealed, which is of great significance to ensure the safety of block cave mining.

\section{Instability Characteristics of Extraction Structure in Tongkuangyu Mine}

The instability characteristics of the extraction structure are mainly manifested on the damage of the production roadway, the collapse of the major apex, the deformation of the undercut roadway, and the dislocation of the ventilation shaft; it is shown in Figure 1.

Based on the site investigation and analysis of the damage area of production level in Tongkuangyu mine, the spatial and temporal evolution process of the instability area of the extraction structure over the years was reviewed, and the following instability laws can be found:

(1) A large proportion of the instability area of the extraction structure occurs in the range of $20-30 \mathrm{~m}$ near the advancing undercut front, which shows the ground pressure failure of the ore drawing and ore loading roadways

(2) With the advancement of undercutting, some instability areas of the extraction structure appear repeated instability after repair, and there is also a certain proportion of instability under the undercut space, which shows the repeated failure of ore drawing and ore loading roadways

(3) With the increase of the undercut area, the damage area of the production level gradually increases, and the ground pressure behavior becomes more intense 


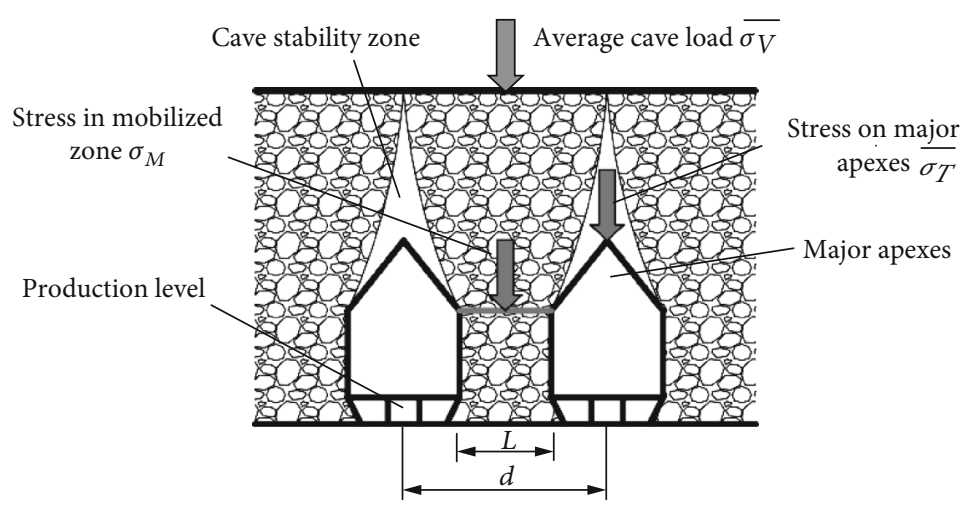

FIGURE 2: Schematic diagram of extraction structure under ore bulk force [11].

\section{Establish of Extraction Structure Numerical Model in Whole Life Cycle}

3.1. Numerical Model Establish Method. The threedimensional finite difference software FLAC $^{3 \mathrm{D}}$ was used to establish the numerical model. FLAC ${ }^{3 \mathrm{D}}$ software is suitable for simulating the stress and deformation of continuous medium, and thus, it has advantages in studying the stress of the extraction structure formation stage and the undercutting stage when the overburden ore does not form caving. However, FLAC ${ }^{3 D}$ is not suitable for the simulation study of overburden rock caving and ore bulk drawing. Particle flow code (PFC) and 3 dimension distinct element code (3DEC) have great advantages in simulating ore bulk flow and ore caving, but it is inefficient in the calculation of a large-scale mining model. It is necessary to design the modeling method reasonably to study the stress of the extraction structure in the ore caving stage by FLAC ${ }^{3 \mathrm{D}}$.

In view of the undercutting stage when the overburden ore did not form the initial caving, three undercut units were preset. The stress state of the extraction structure after excavation of each undercut unit was monitored, respectively. It could be used to study the stress evolution of the extraction structure with the increase of the undercut area.

The study of stress evolution law of the extraction structure during the caving stage did not involve the display of caving process, and only studied the stress state of the extraction structure before and after ore caving in the process of undercutting. Therefore, in the process of modeling, the command flow could be used to manually excavate the preset three domed caving areas step by step. The scope of the caving area was determined according to the following principles, the approximate range was firstly determined according to the plastic zone of overburden strata simulated by each step of undercutting, and then, the optimization was carried out according to the observed caving range in the upper panel roadway of the mine. After the area of undercut unit reaches the area of initial caving, the first domed caving area was excavated manually with command flow. With the advancement of undercutting, the other two caving areas were excavated manually in turn. Thus, the dynamic process of collapse could be transformed into a static process, and the stress evolution law of the extraction structure in the process of caving stage could be monitored and studied.

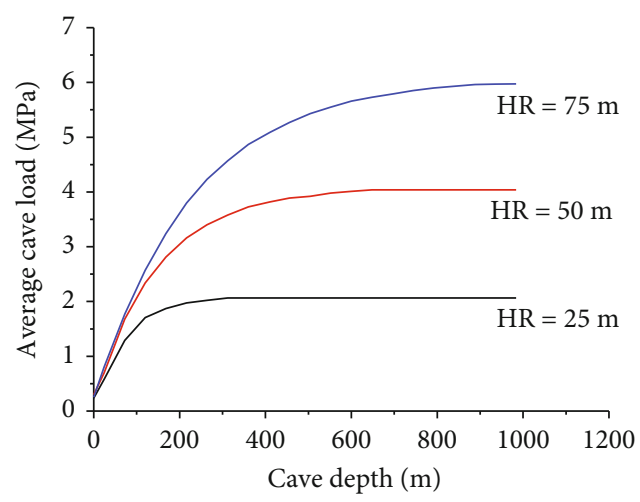

FIGURE 3: Function diagram of average stress at the bottom of ore bulk [11].

The model of the ore drawing stage after overburden ore caving was established by drawing on the conclusion of force analysis of ore bulk on the extraction structure studied by Pierce [9]. The stress of ore bulk acting on the extraction structure is mainly transferred through the major apexes. In the process of ore drawing, the flow of internal ore produces the equilibrium stress arch. Due to the influence of the equilibrium arch of the ore bulk, the vertical stress on the top of the major apexes is different from that on the bottom of the ore bulk, and it is shown in Figure 2. From formula (1), the stress acting on the top of the major apexes is 1.6 times as large as the average vertical stress at the bottom of the ore bulk in the stope.

$$
\frac{\bar{\sigma}_{T}}{\sigma_{V}}=\frac{d}{d-l},
$$

where $\mathrm{d}$ is the distance between the adjacent ore loading roadway, and it is $30 \mathrm{~m}$ in Tongkuangyu mine and 1 is the length of drawbell, and it is $11 \mathrm{~m}$ in Tongkuangyu mine. The buried depth of undercut level in the main sublevel in the 530 panel in Tongkuangyu mine is $536 \mathrm{~m}$. The average vertical stress at the bottom of ore bulk in stope is about $1.5 \mathrm{MPa}$ by interpolation according to the functional relationship in Figure 3. Thus, the vertical stress acting on the top of the major apex is $2.4 \mathrm{MPa}$. A uniform stress of 2.4 MPa can be applied at the tip of the major apexes below 


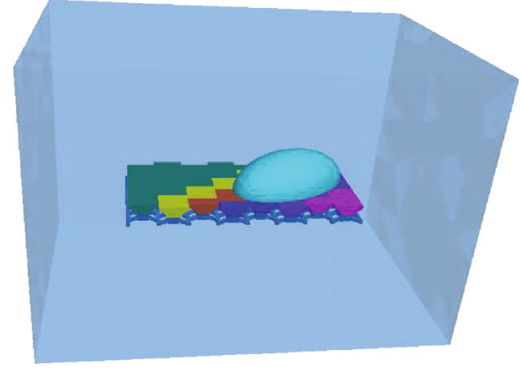

(a)

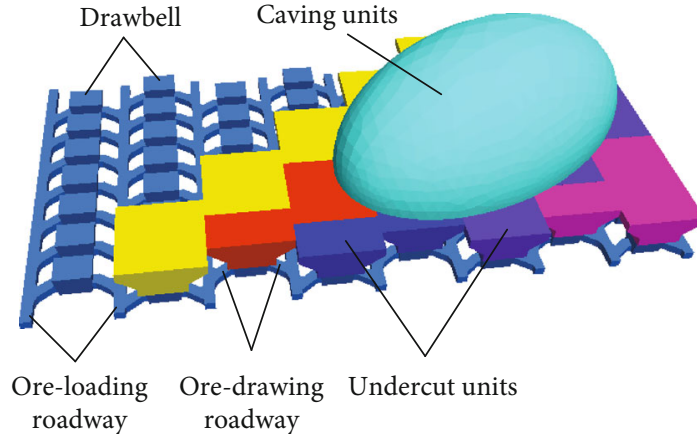

(b)

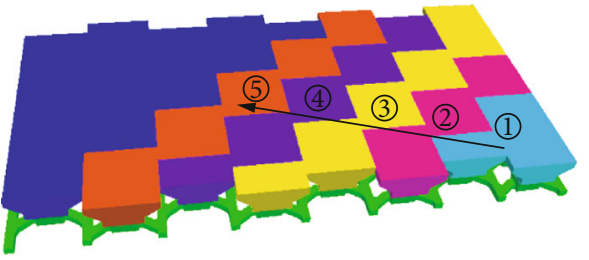

(c)

Figure 4: Numerical model: (a) overall structure of the model, (b) internal structure of the model, and (c) excavation sequence of the undercut unit.

TABLE 1: Rock mass mechanical parameters in the numerical model.

\begin{tabular}{|c|c|c|c|c|c|c|c|}
\hline Items & $\begin{array}{c}\text { Elasticity modulus, } \\
E(\mathrm{GPa}) \\
\end{array}$ & $\begin{array}{c}\text { Bulk density, } \\
\rho\left(\mathrm{kg} / \mathrm{m}^{3}\right)\end{array}$ & $\begin{array}{c}\text { Cohesive strength, } \\
C(\mathrm{MPa})\end{array}$ & $\begin{array}{c}\text { Shear modulus, } \\
G(\mathrm{GPa})\end{array}$ & $\begin{array}{c}\text { Internal friction } \\
\text { angle, } \varphi\left(^{\circ}\right)\end{array}$ & $\begin{array}{c}\text { Tensile strength, } \\
\sigma_{t}(\mathrm{MPa})\end{array}$ & $\begin{array}{l}\text { Poisson } \\
\text { ratio, } \mu\end{array}$ \\
\hline Value & 5.99 & 2740 & 6.6 & 2.45 & 42.58 & 6.62 & 0.22 \\
\hline
\end{tabular}

the caving space to replace the ore bulk in the ore drawing process above the extraction structure. Therefore, the dynamic simulation of the discontinuous medium was transformed into the static simulation of the continuous medium, and the stress evolution process of extraction structure in the ore drawing stage can be studied.

To sum up, through a reasonable conception of the modeling method and numerical simulation based on three-dimensional finite difference software FLAC ${ }^{3 \mathrm{D}}$, the stress evolution process in the whole life cycle of the extraction structure could be effectively studied, and then, the instability mechanism of extraction structure could be explored.

3.2. Model Structure Parameters. The overall structure of the model is shown in Figure 4(a), and the internal structure of the model is shown in Figure 4(b). The range of the model is taken from the local range of the main sublevel in the 530 panel of the No.4 orebody in Tongkuangyu mine. The model has $410 \mathrm{~m}$ strike length, $291 \mathrm{~m}$ vertical strike length, and $310 \mathrm{~m}$ height, and 1942313 units in total. According to the needs of the research content, a total of 9 ore loading roadways, 60 ore drawing roadways, and 60 drawbells are arranged at the production level, and the burial depth of production level is $545 \mathrm{~m}$. The top open face of the drawbell is $13 \mathrm{~m} \times 10 \mathrm{~m}$ (length $\times$ width), the bottom open face is $11 \mathrm{~m}$ $\times 6.4 \mathrm{~m}$ (length $\times$ width), and the height is $10 \mathrm{~m}$. The net cross-section of ore drawing roadways and ore loading roadways is $3.8 \mathrm{~m} \times 3.2 \mathrm{~m}$ (width $\times$ height). The distance between the production level and the undercut level is $10 \mathrm{~m}$; the dis- tance between the adjacent ore loading roadway is $30 \mathrm{~m}$; the ore drawing roadways are arranged in the branch herring bone type with the distance of $15 \mathrm{~m}$. The undercut level is arranged above the extraction structure, and five undercut units are arranged from right to left. The undercut height is $12 \mathrm{~m}$, and the undercut units are arranged in the diagonal direction step by step, which makes the simulation more in line with the actual situation of undercutting in Tongkuangyu mine. Three caving units are arranged above the undercut level; it is shown in Figure 4(b).

3.3. Strength Criteria and Boundary Conditions. The MohrCoulomb criterion was used in this calculation. Many parameters in the Hoek-Brown criterion could calculate rock mass failure with fissures [19-21]. In order to effectively describe the influence of fissures on the strength of rock mass in the numerical model, the equivalent calculation of some parameters was needed between the HoekBrown criterion and Mohr-Coulomb criterion. The rock mass mechanical parameters in the numerical model are shown in Table 1.

The vertical stress in the numerical model changes linearly with the depth. According to the buried depth of the ore body and the average rock mass density, the vertical stress was applied on the top plane of the model. The measured in situ stress was applied inside the model, the horizontal movement is limited on the side of the model, and the vertical movement is limited on the bottom plane of the model. 

lows:

The in situ stresses applied inside the model are as fol-

$$
\begin{gathered}
\sigma_{\mathrm{x}}=22.8954-0.0399 Z, \\
\sigma_{y}=11.6484-0.0204 Z, \\
\sigma_{z}=14.6600-0.0269 Z .
\end{gathered}
$$

3.4. Numerical Simulation Steps of Extraction Structure in Whole Life Cycle. The simulation process of the numerical model was carried out according to the actual undercutting mode of Tongkuangyu mine. The extraction structure was formed firstly, and then, the undercutting level was excavated; the specific steps were as follows:

(1) The three-dimensional model was established, and the initial stress and boundary conditions were applied to form the initial equilibrium. At this time, the rock mass was in the in situ stress state

(2) The extraction structure was formed by excavating ore loading roadways, ore drawing roadways, and drawbells

(3) The undercut level was divided into five units along the diagonal direction and was pushed in ladder type, as shown in Figure 4(c); each color represented one undercut unit. Two undercut units were excavated step by step to form major apexes firstly; the initial caving was not formed in this stage. The stress and displacement state of major apexes and production roadways were monitored and analyzed

(4) With the excavation of the remaining three undercut units step by step, three ore caving areas were excavated in turn, which represented the continuous caving of overburden ore. At the same time, the vertical downward uniform stress was applied on the major apexes formed under the caving area, which represented the stress exerted on the extraction structure by the ore bulk. The stress and displacement state of major apexes and production roadways were monitored and analyzed

\section{Mechanical Effect of Extraction Structure in Whole Life Cycle}

\subsection{Stress Evolution Characteristics of Extraction Structure in Whole Life Cycle}

\subsubsection{Evolution Characteristics of Maximum Principal Stress} of Extraction Structure. The evolution characteristic contour of the maximum principal stress in the $X O Y$ cutting plane of the production level in each stage is shown in Figure 5, and the evolution characteristic contour of the maximum principal stress of in the $X O Z$ cutting plane of the extraction structure are shown in Figure 6. In all contours, the negative value represents the compressive stress, and the positive value represents the tensile stress. The red area in the contour is the high stress concentration area of the maximum principal stress, and its value negative, so it exists in the form of compressive stress.

The extraction structure is formed after excavating ore loading roadways, ore drawing roadways, and drawbells. It can be seen from Figures 5(a) and 6(a) that the compressive stress is concentrated on the two sidewalls of the ore loading roadways and ore drawing roadways in a small range, the maximum value is $40.5 \mathrm{MPa}$, and the stress concentration factor is 1.8. Most range of the whole extraction structure is not in the stress concentration area, so the overall stability of the extraction structure is not affected when the excavation is completed.

It can be seen from Figures 5(b)-5(d), with the advancement of undercutting, the compressive stress concentration on the production level under the undercut space is gradually released. The maximum principal stress is positive, so it turns into the state of tensile stress. There is only a small range of compressive stress concentration at the production level under the undercut boundary on the right side. The compressive stress concentration gradually shifts to near the advancing undercut front, and the area of compressive stress concentration gradually expands. The stress concentration on the first ore loading roadways and ore drawing roadways in front of the advancing undercut front increases obviously after undercutting. After excavation of the third undercut unit, the maximum compressive stress of the production level near the advancing undercut front reaches $46.2 \mathrm{MPa}$, which is 12.7 percent higher than that of the extraction structure initially formed, and the compressive stress concentration factor reaches 2. As shown in Figures 6(b)-6(d), after the formation of the major apex, it is in the area where the compressive stress decreases.

With the continuous increase of the undercut area, the overburden ore collapses after reaching the hydraulic radius. As shown in Figures 5(d) and 5(e), the concentration degree of compressive stress of production level near the advancing undercut front slightly decreases after the overburden ore caving. As shown in Figures 5(e)-5(g), with the continuous caving of overburden ore, the compressive stress of production level near the advancing undercut front continues to increase. The maximum compressive stress of the ore drawing level in front of the advancing line reaches 53.2 MPa after excavation of the fifth undercut unit and third caving unit, which is 29.5 percent higher than that of the extraction structure initially formed, and the compressive stress concentration factor reaches 2.3 .

4.1.2. Evolution Characteristics of Minimum Principal Stress of Extraction Structure. The evolution characteristics contour of the minimum principal stress in the XOY cutting plane of the production level in each stage are shown in Figure 7, and the evolution characteristic contour of the minimum principal stress in the $X O Z$ cutting plane of the extraction structure are shown in Figure 8. The red area in the contour is the high stress concentration area of the minimum principal stress, which is positive, so it exists in the form of tensile stress.

The extraction structure is formed after excavating ore loading roadways, ore drawing roadways, and drawbells. It can be seen from Figures 7(a) and 8(a) that the tensile stress 


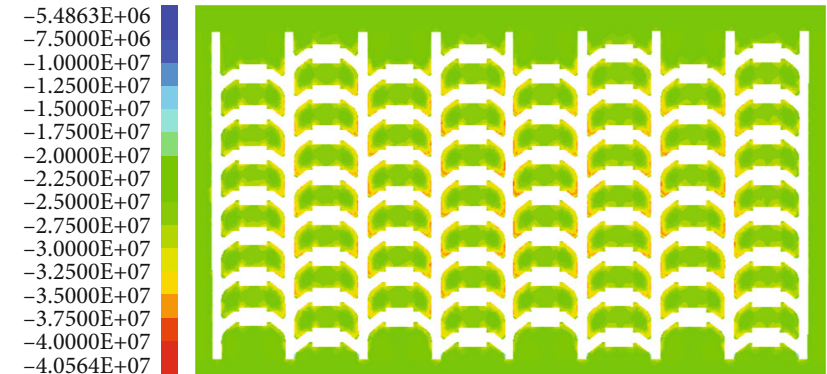

(a)

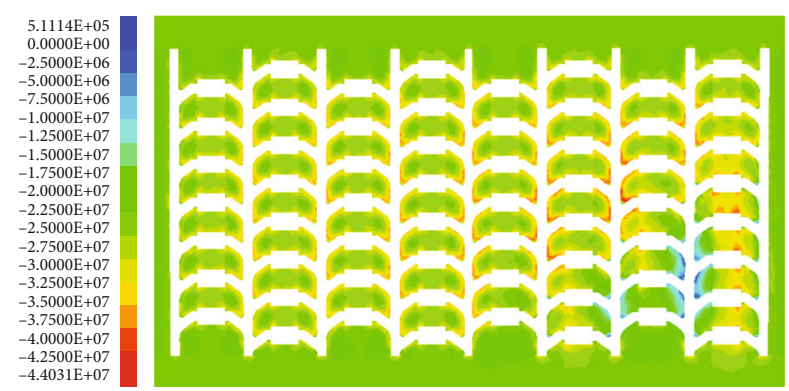

(c)

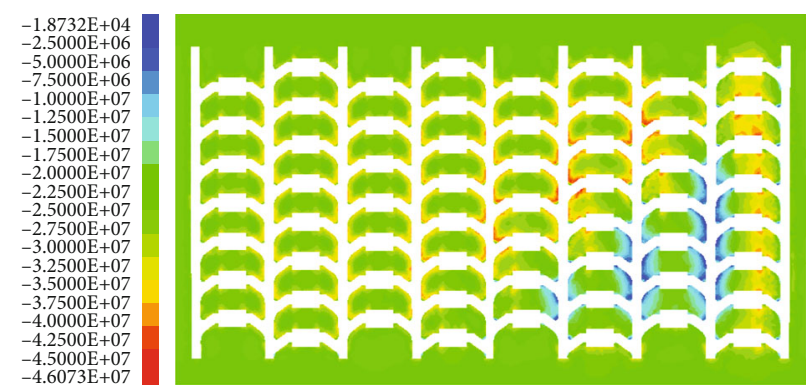

(e)
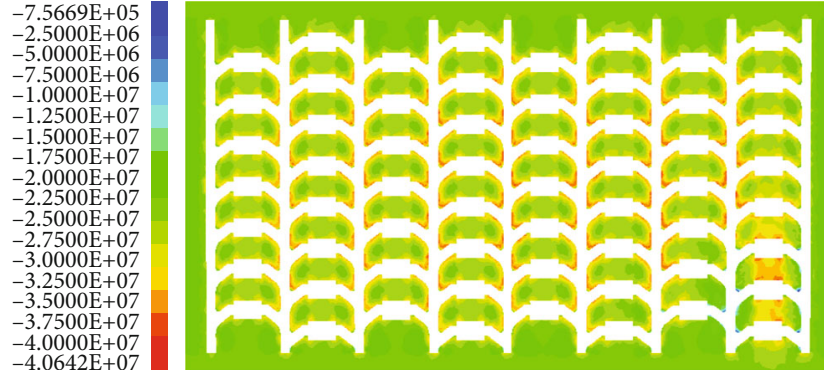

(b)
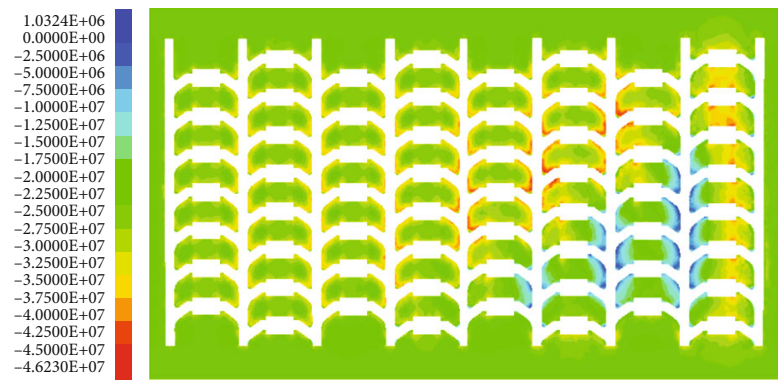

(d)

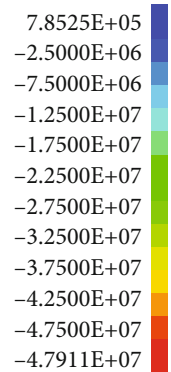

$-4.7911 \mathrm{E}+07$

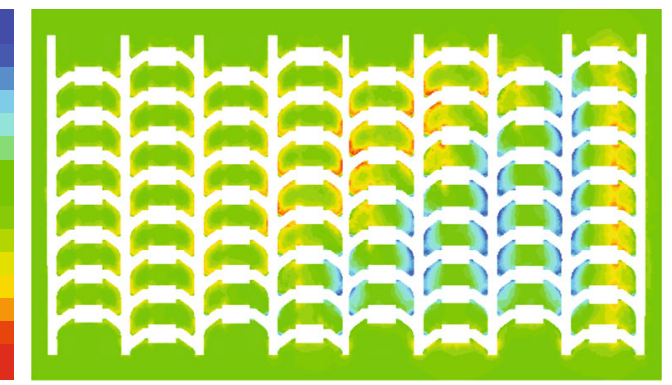

(f)

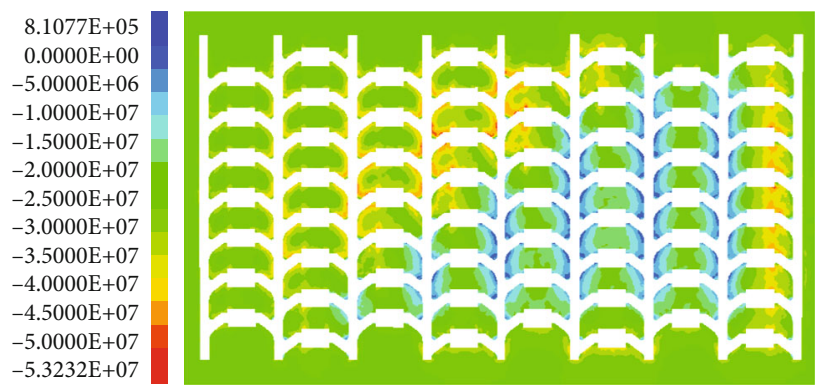

(g)

FIgURE 5: Evolution characteristic contour of the maximum principal stress in the XOY cutting plane of the production level: (a) after the formation of the extraction structure, (b) after excavation of the first undercut unit, (c) after excavation of the second undercut unit, (d) after excavation of the third undercut unit, (e) after initial caving, (f) after excavation of the fourth undercut unit and second caving unit, and $(\mathrm{g})$ after excavation of the fifth undercut unit and third caving unit.

is concentrated on the intersections of the ore loading roadways and ore drawing roadways in a small range; the minimum value is $2.5 \mathrm{MPa}$. Most range of the whole extraction structure is not in the stress concentration area, so the overall stability of the extraction structure is not affected when the excavation is completed. By comparing Figure 5(a) with Figure $7(\mathrm{a})$, it is found that tensile stress concentration rather than compressive stress concentration is easy to occur at the intersections of ore loading roadways and ore drawing roadways after the extraction structure formation.

It can be seen from Figures 7(c) and 8(d) that, with the advancement of undercutting, the tensile stress concentration on the production level under the undercut space is gradually obvious, and the disturbance is gradually increased. At the initial stage of the formation of the extraction structure, tensile stress concentration was on the intersections. 

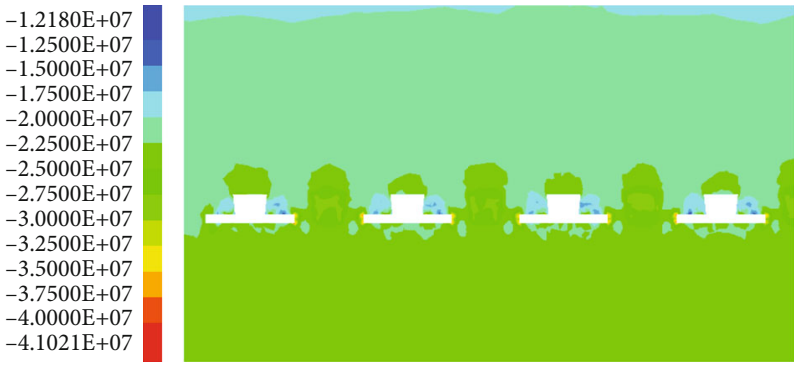

(a)
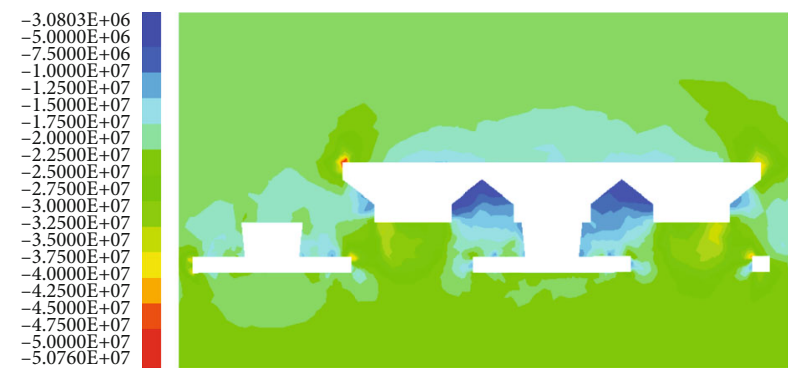

(c)
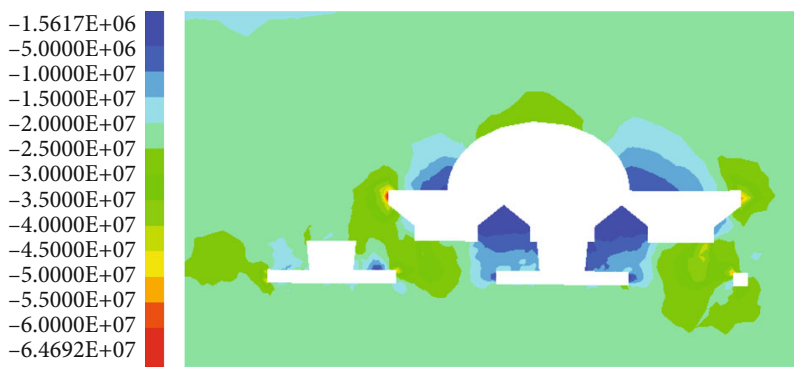

(e)
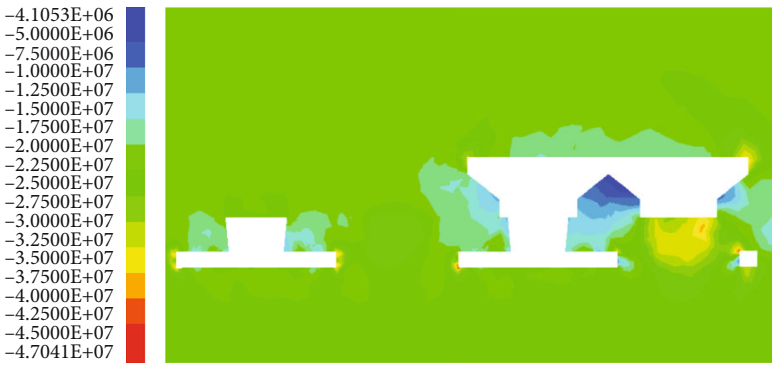

(b)

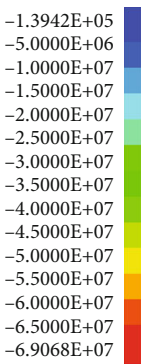

$-6.9068 \mathrm{E}+07$

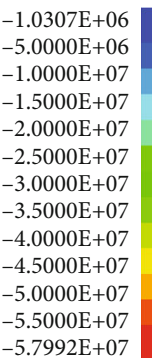

$-5.7992 \mathrm{E}+07$

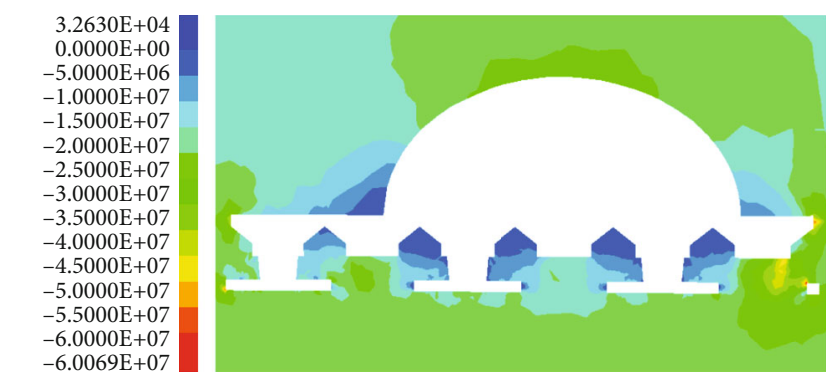

(g)

Figure 6: Evolution characteristic contour of the maximum principal stress in the XOZ cutting plane of the extraction structure: (a) after the formation of the extraction structure, (b) after excavation of the first undercut unit, (c) after excavation of the second undercut unit, (d) after excavation of the third undercut unit, (e) after initial caving, (f) after excavation of the fourth undercut unit and second caving unit, and (g) after excavation of the fifth undercut unit and third caving unit.

After excavation of the third undercut unit, both sidewalls of the ore loading roadways and ore drawing roadways under the undercut space are affected by high tensile stress. The maximum tensile stress is $5.8 \mathrm{MPa}$, which is 1.3 times as large as the extraction structure initially formed. It can be seen from Figures $8(\mathrm{~b})-8(\mathrm{~d})$ that the tensile stress is concentrated on the tip of the pillar after the major apex formation; after three steps of undercutting, the maximum tensile stress on the tip of major apex increases from $2 \mathrm{MPa}$ to $4 \mathrm{MPa}$.
With the continuous increase of the undercut area, the overburden ore caves and the ore bulk fall on the extraction structure under the undercut space. At this time, the orderly ore drawing is carried out. It can be seen from Figures $7(\mathrm{~d})-$ $7(\mathrm{e})$ and $8(\mathrm{~d})-8(\mathrm{e})$ that, after the ore body bulk falls down and starts to extract ores, the maximum tensile stress concentrated on the two sidewalls of ore loading roadways and ore drawing roadways under the undercut space decreases from $5.8 \mathrm{MPa}$ to $3.8 \mathrm{MPa}$, and the maximum tensile stress 


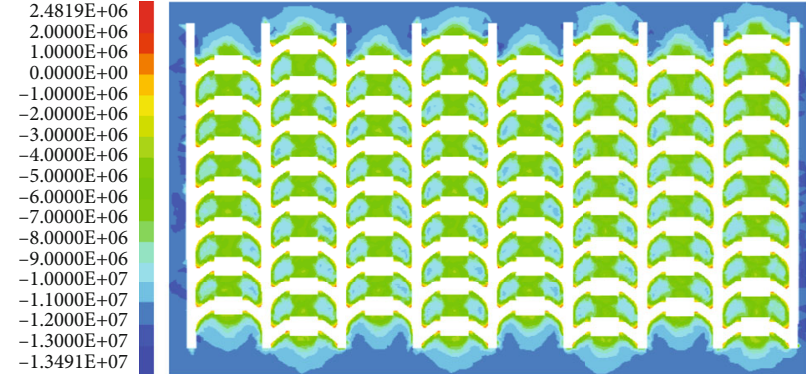

(a)

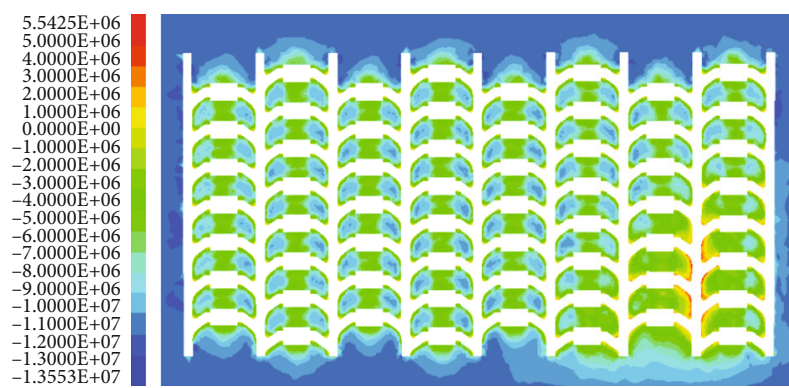

(c)

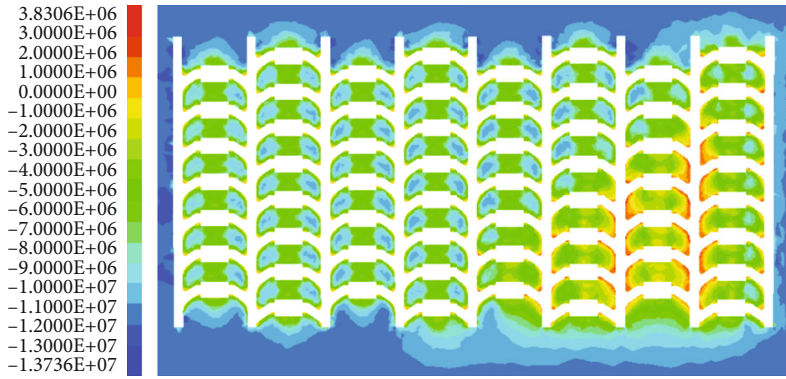

(e)

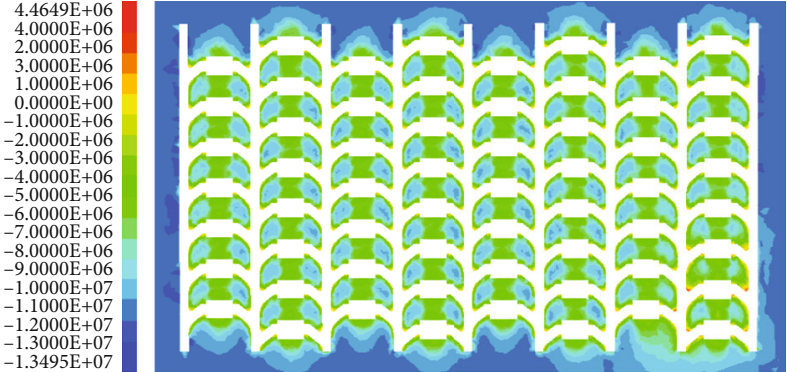

(b)
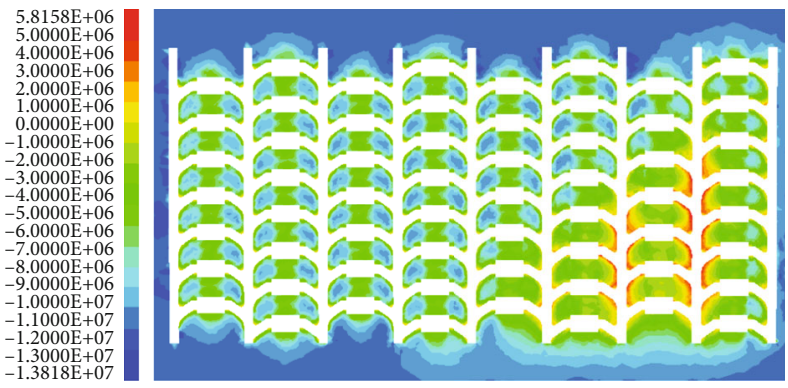

(d)
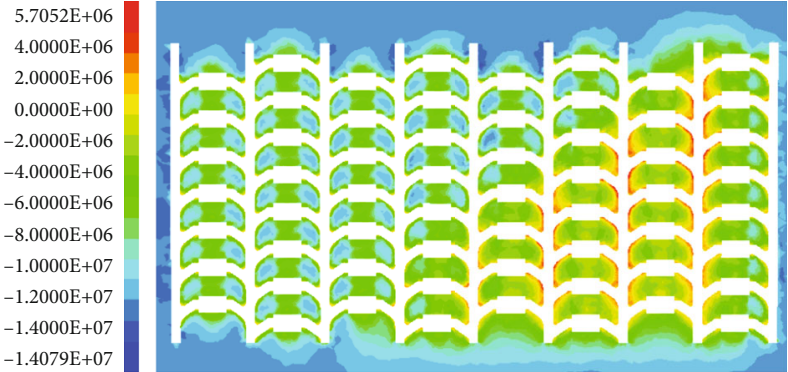

(f)

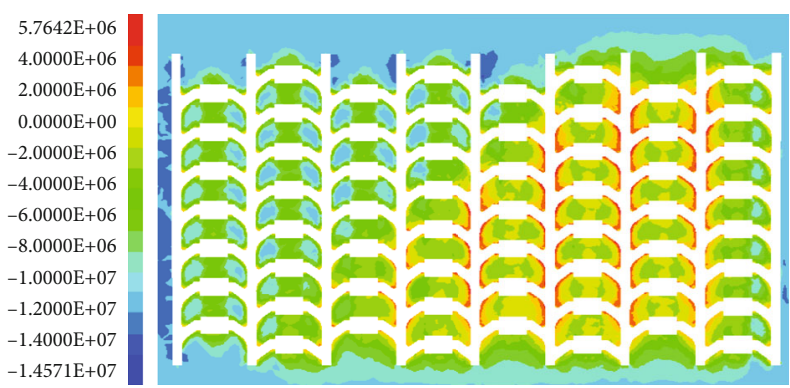

(g)

FIgURE 7: Evolution characteristic contour of the minimum principal stress in the XOY cutting plane of the production level: (a) after the formation of the extraction structure, (b) after excavation of the first undercut unit, (c) after excavation of the second undercut unit, (d) after excavation of the third undercut unit, (e) after initial caving, (f) after excavation of the fourth undercut unit and second caving unit, and $(\mathrm{g})$ after excavation of the fifth undercut unit and third caving unit.

concentrated on the major apex decreases from $4 \mathrm{MPa}$ to 2.5 MPa. The range of tensile stress concentration on the extraction structure is also slightly reduced, so the ore bulk on the extraction structure can effectively reduce the tensile stress concentration of the extraction structure under the undercut space. It can be seen from Figures $7(\mathrm{e})-7(\mathrm{~g})$, with the advance of undercutting, the continuous caving of the overburden ore, and the orderly ore drawing, the tensile stress concentrated on the two sidewalls of ore loading road- ways and ore drawing roadways under the undercut space gradually increases; after excavation of the fifth undercut unit and third caving unit, the maximum tensile stress increases to $5.7 \mathrm{MPa}$. It can be seen from Figures $8(\mathrm{e})-8(\mathrm{~g})$ that, with the continuous process of undercutting and caving, the ore bulk accumulated on the extraction structure increases gradually, the ore drawing point also increases gradually, and the range of tensile stress concentration on the extraction structure decreases gradually, but the tensile stress concentrated 


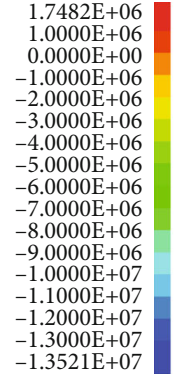

$1.3521 \mathrm{E}+07$

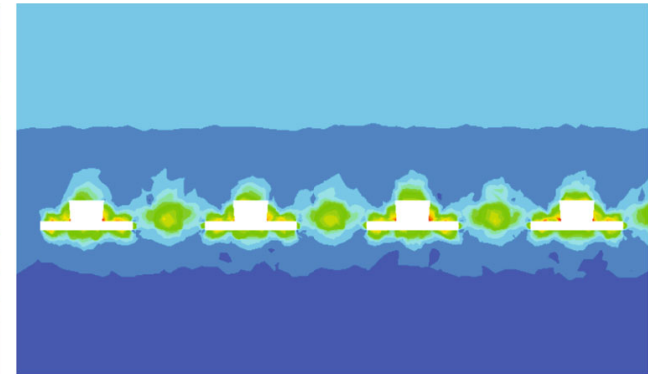

(a)

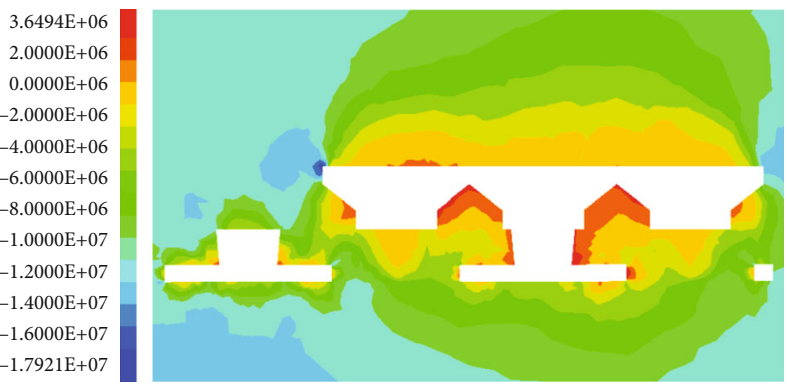

(c)

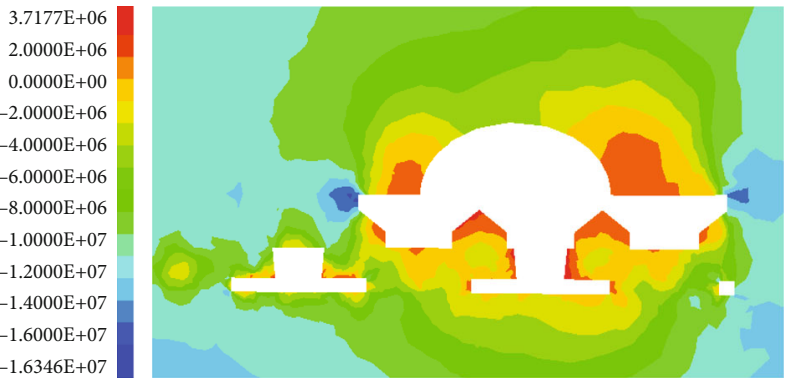

(e)

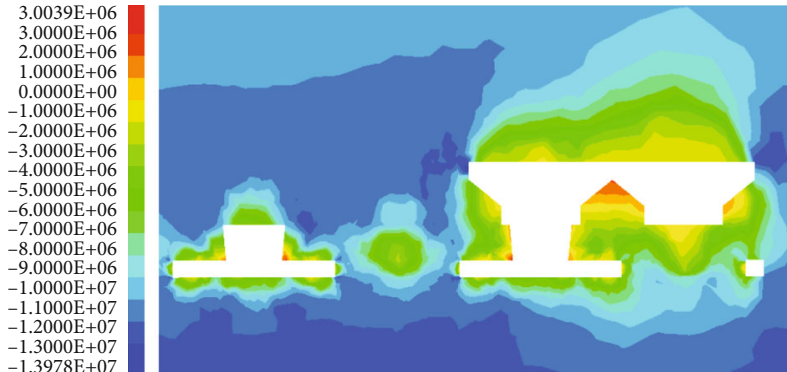

(b)
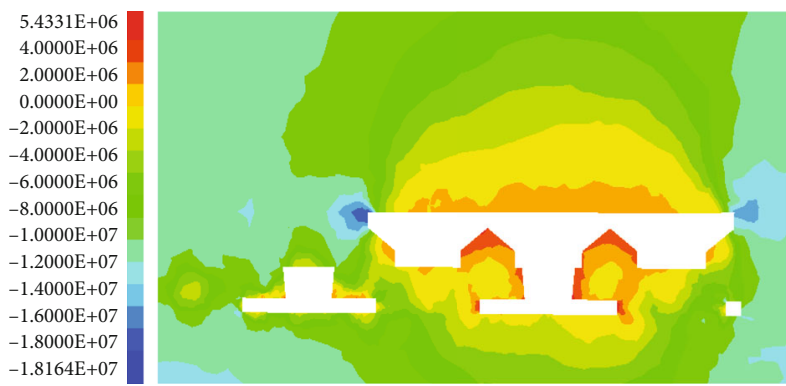

(d)

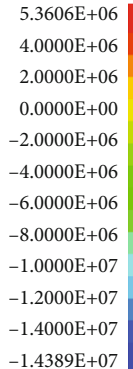

$-1.4389 \mathrm{E}+07$

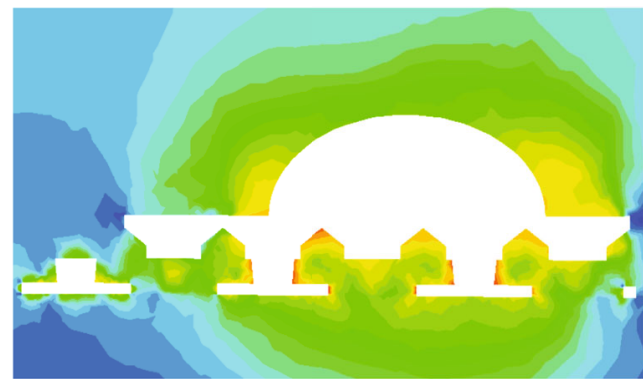

(f)

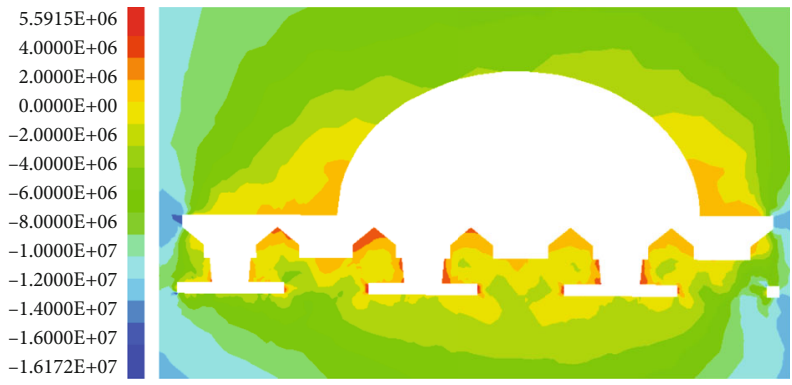

(g)

FIGURE 8: Evolution characteristic contour of the minimum principal stress in the $X O Z$ cutting plane of the extraction structure: (a) after the formation of the extraction structure, (b) after excavation of the first undercut unit, (c) after excavation of the second undercut unit, (d) after excavation of the third undercut unit, (e) after initial caving, (f) after excavation of the fourth undercut unit and second caving unit, and (g) after excavation of the fifth undercut unit and third caving unit.

on the tip of major apex continues to increase. After excavation of the fifth undercut unit and third caving unit, the maximum tensile stress concentrated on the tip of major apex reaches $4 \mathrm{MPa}$.

It can be seen from the comparison of Figures 5 and 7 , with the advancement of undercutting, the production level near the advancing undercut front gradually shifts to the location under the undercut space, and the high compressive stress concentrated on the two sidewalls of ore loading road- ways and ore drawing roadways gradually turns to high tensile stress concentration.

\subsection{Displacement Evolution Characteristics of Extraction Structure in Whole Life Cycle}

4.2.1. Evolution Characteristics of Horizontal Displacement of Extraction Structure. The evolution characteristic contour of the horizontal displacement in the XOY cutting plane of the 

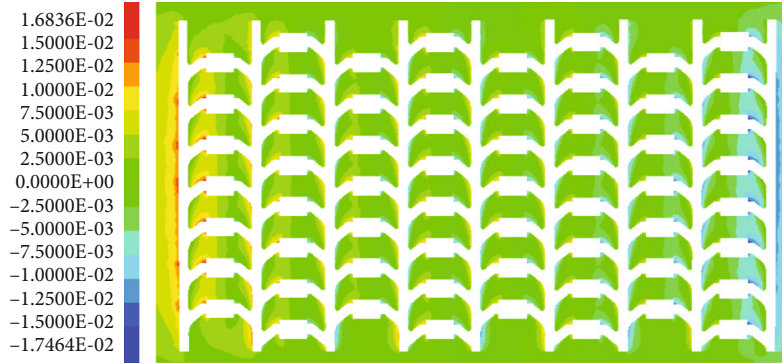

(a)

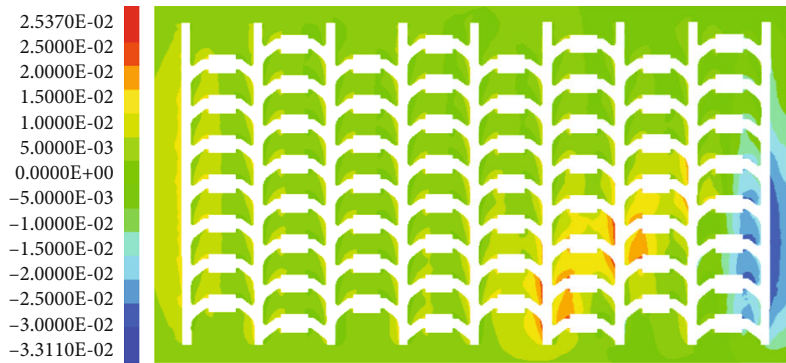

(c)

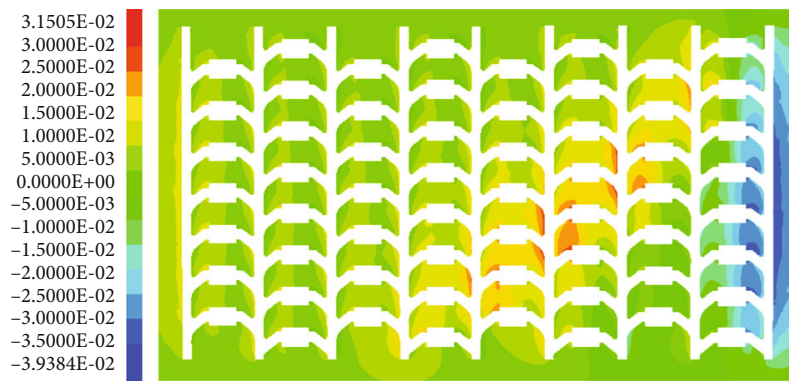

(e)

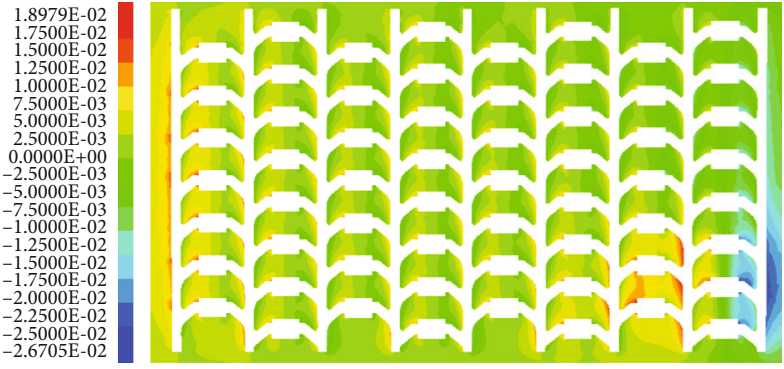

(b)

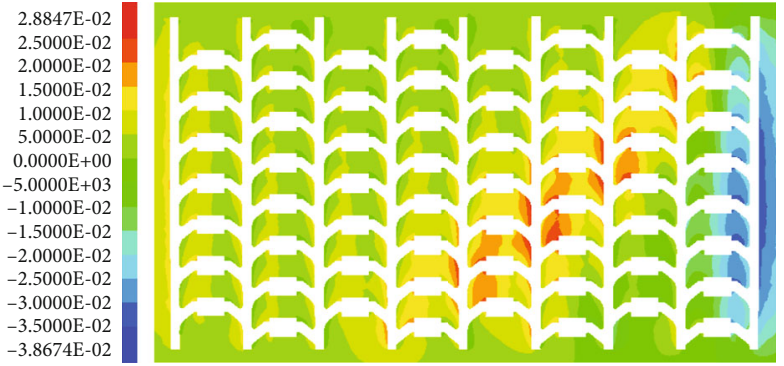

(d)

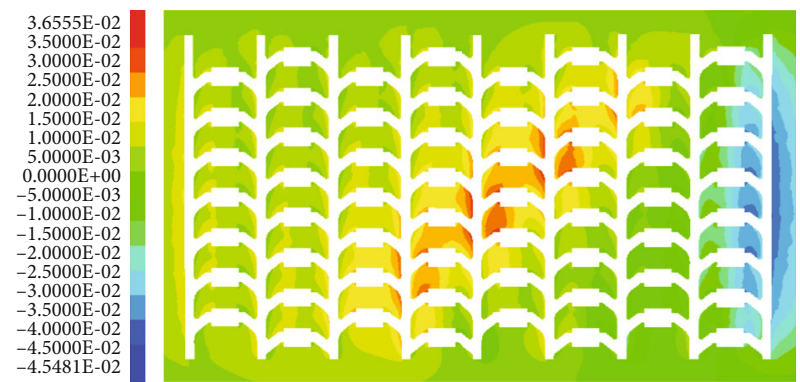

(f)

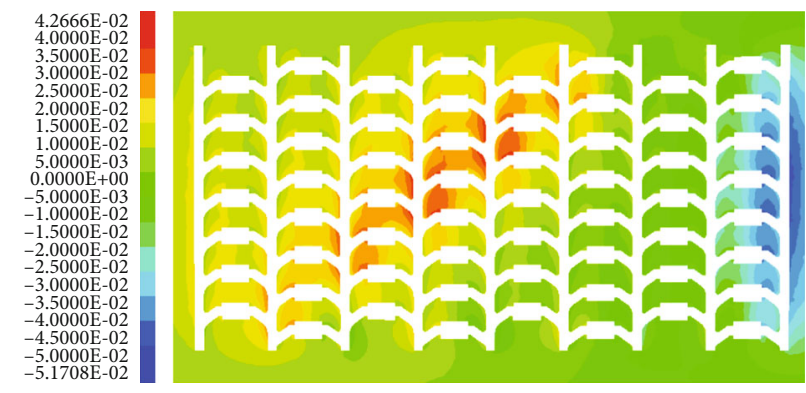

(g)

FIgURE 9: Evolution characteristic contour of the horizontal displacement in the XOY cutting plane of the production level: (a) after the formation of the extraction structure, (b) after excavation of the first undercut unit, (c) after excavation of the second undercut unit, (d) after excavation of the third undercut unit, (e) after initial caving, (f) after excavation of the fourth undercut unit and second caving unit, and $(\mathrm{g})$ after excavation of the fifth undercut unit and third caving unit.

production level in each stage are shown in Figure 9, and the evolution characteristic contour of the horizontal displacement of the $\mathrm{XOZ}$ cutting plane of the extraction structure are shown in Figure 10. The red area in the contour is the area with larger displacement along the positive directions of $x$ -axis, and the blue area in the contour is the area with larger displacement along negative directions of the $x$-axis.

The extraction structure is formed after excavating ore loading roadways, ore drawing roadways, and drawbells. It can be seen from Figure 9(a) that the sidewalls of ore loading roadways located on the boundary of production level are deformed, the sidewalls wall of ore loading roadways located on the left boundary is deformed to the right, and the sidewalls of ore loading roadways located on the right boundary is deformed to the left; the maximum value is only $16.8 \mathrm{~mm}$. It can be seen from Figure 10(a) that the two sidewalls of drawbells move closer; the maximum horizontal displacement value is $18.3 \mathrm{~mm}$. In general, the displacement of the roadway is not large after the initial formation of the extraction structure, which cannot affect the mining production. 

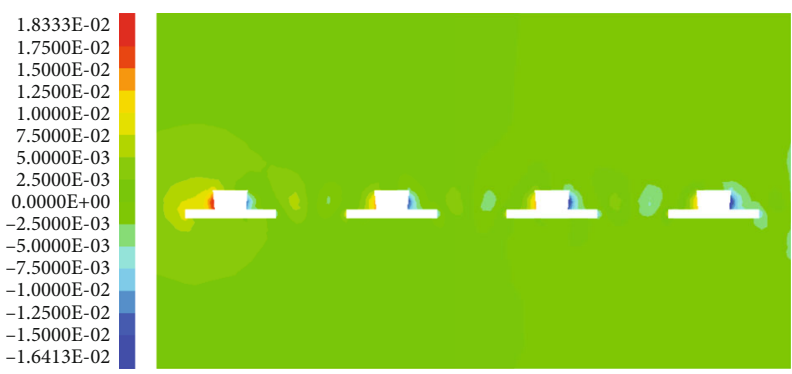

(a)

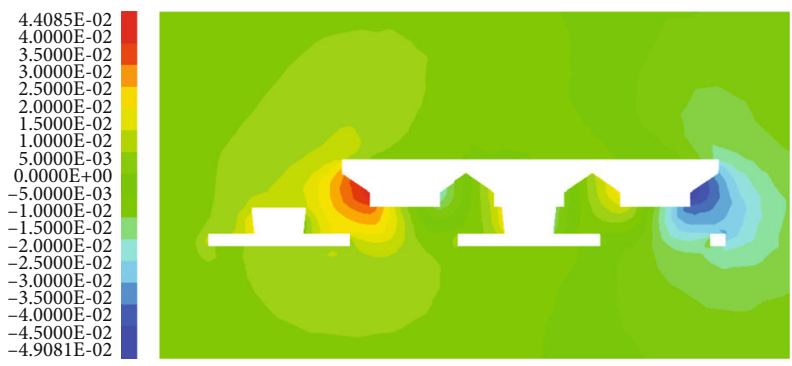

(c)

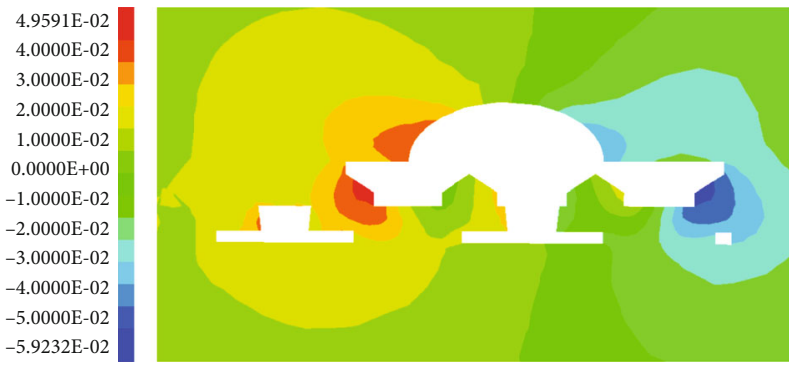

(e)

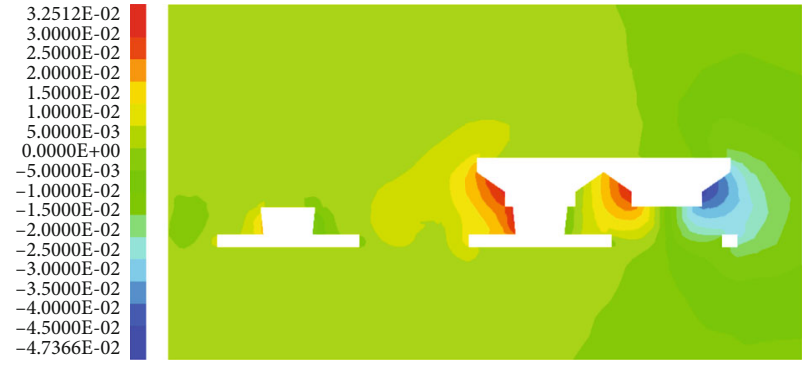

(b)
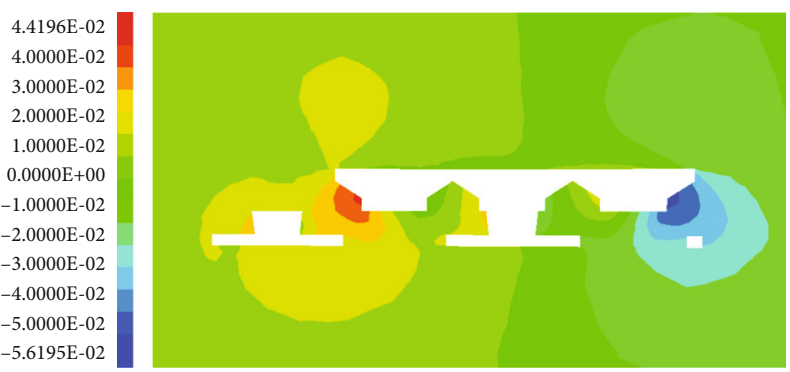

(d)

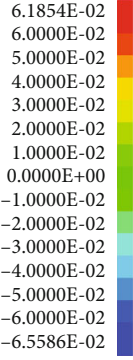

$-6.0000 \mathrm{E}-02$

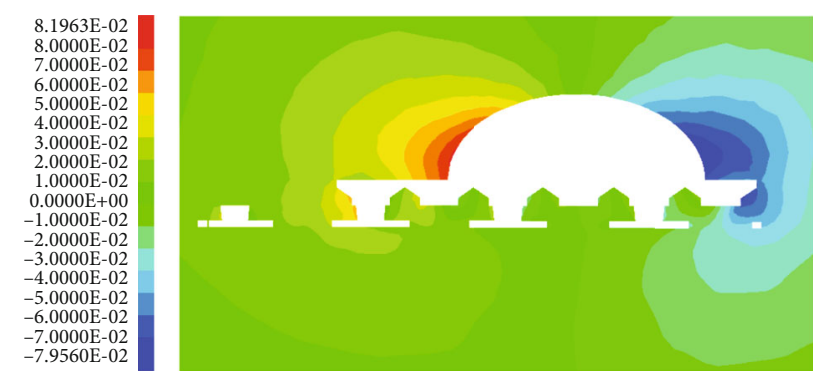

(g)

FIGURE 10: Evolution characteristic contour of the horizontal displacement in the XOZ cutting plane of the extraction structure: (a) after the formation of the extraction structure, (b) after excavation of the first undercut unit, (c) after excavation of the second undercut unit, (d) after excavation of the third undercut unit, (e) after initial caving, (f) after excavation of the fourth undercut unit and second caving unit, and (g) after excavation of the fifth undercut unit and third caving unit.

It can be seen from Figures $9(\mathrm{~b})-9(\mathrm{~d})$ that, with the advancement of undercutting, the sidewalls of ore loading roadways near the advancing undercut front are deformed to the right, and the displacement of the left sidewall is larger than that of the right sidewall; moreover, the displacement increases with the increase of the undercut area. After three steps of undercutting, the displacement value increases from $18.9 \mathrm{~mm}$ to $28.8 \mathrm{~mm}$. It can be seen from Figures 10(b)-10(d) that the left sidewalls of the first drawbells near the undercut front are deformed to the right; after three steps of undercutting, the displacement increases from $18.3 \mathrm{~mm}$ to $30.2 \mathrm{~mm}$.
The displacement of major apexes near the undercut front is deformed to the right; after three steps of undercutting, the displacement increases from $18.3 \mathrm{~mm}$ to $30.2 \mathrm{~mm}$.

It can be seen from Figures $9(\mathrm{e})-9(\mathrm{~g})$ and $10(\mathrm{e})-10(\mathrm{~g})$ that, after the overburden ore caving, with the continuous increase of the undercut area, the deformation of ore loading roadways, major apexes, and drawbells at the undercutting boundary increases continuously. After excavation of the fifth undercut unit and third caving unit, the maximum displacement of the sidewalls of ore loading roadways near the advancing undercut front increases to $42.6 \mathrm{~mm}$, and the 


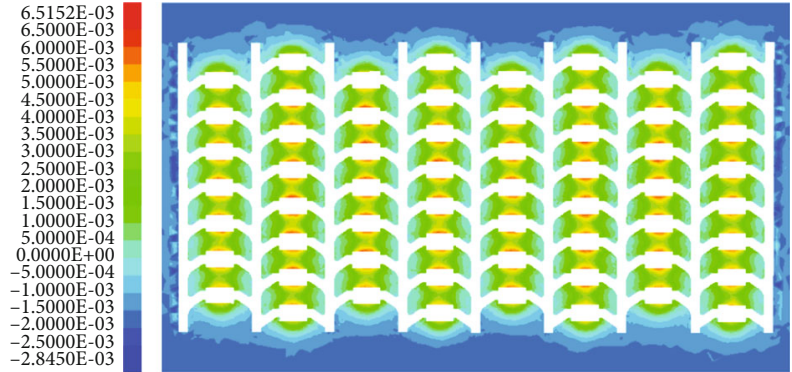

(a)

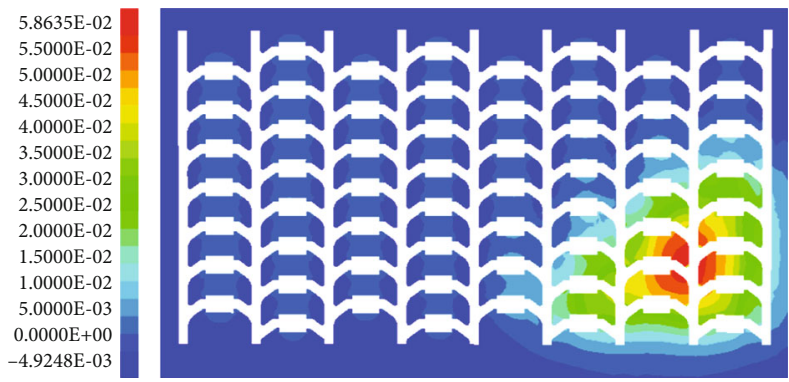

(c)

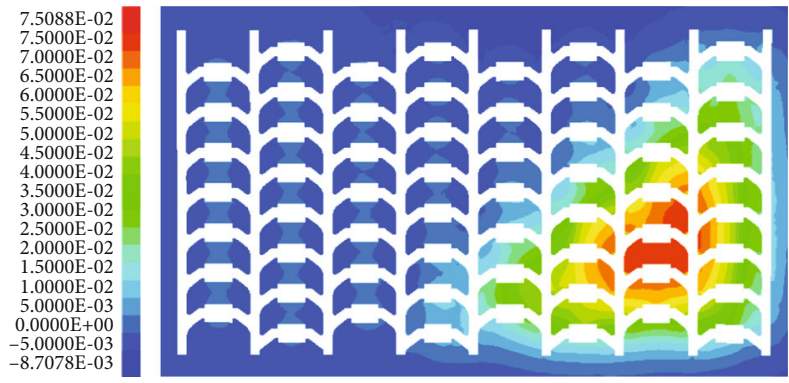

(e)

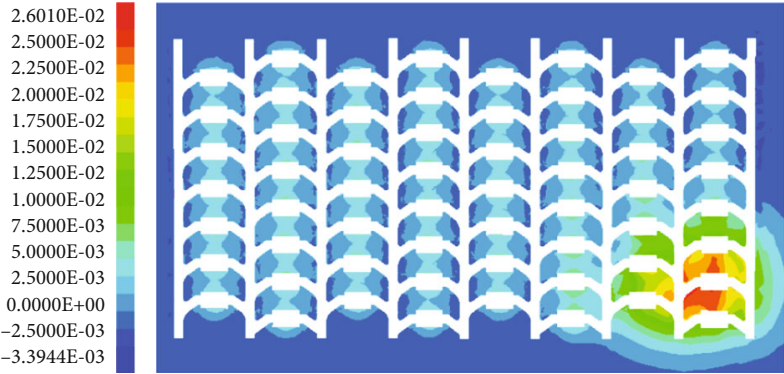

(b)

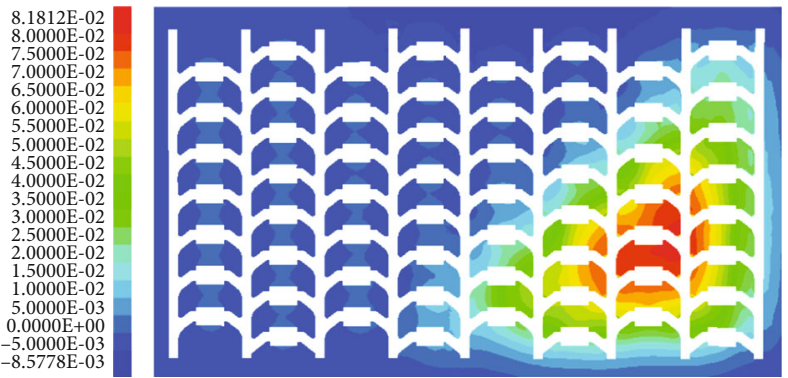

(d)
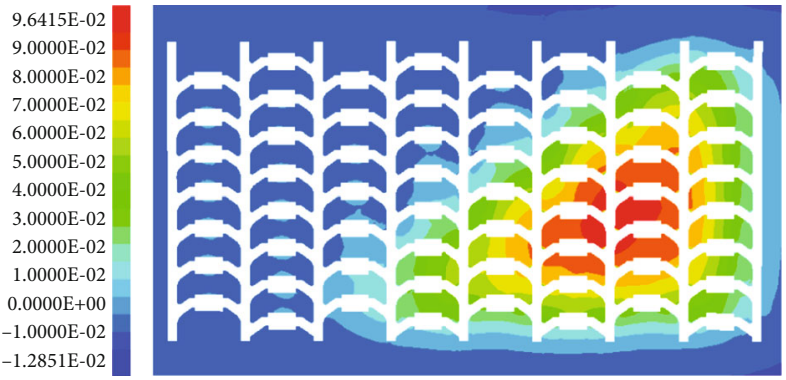

(f)

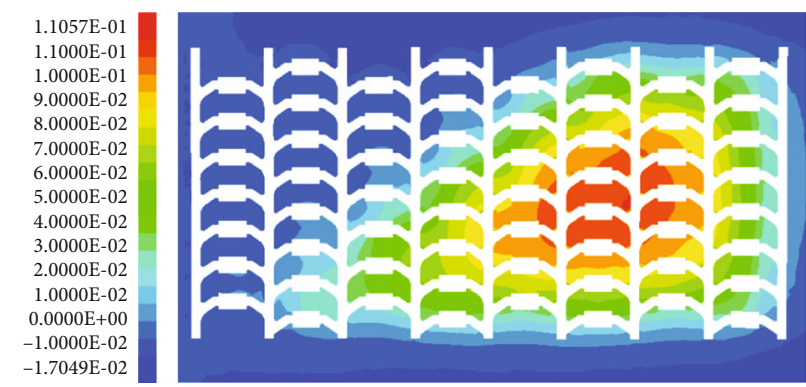

(g)

FIGURE 11: Evolution characteristic contour of the vertical displacement in the XOY cutting plane of the production level: (a) after the formation of the extraction structure, (b) after excavation of the first undercut unit, (c) after excavation of the second undercut unit, (d) after excavation of the third undercut unit, (e) after initial caving, (f) after excavation of the fourth undercut unit and second caving unit, and $(\mathrm{g})$ after excavation of the fifth undercut unit and third caving unit.

maximum horizontal displacement of the sidewalls of ore loading roadways, major apexes, and drawbells near the advancing undercut front increases to $42.6 \mathrm{~mm}, 53.4 \mathrm{~mm}$, and $53 \mathrm{~mm}$, respectively.

\subsubsection{Evolution Characteristics of Vertical Displacement of} Extraction Structure. The evolution characteristic contour of the vertical displacement in the XOY cutting plane of the production level in each stage are shown in Figure 11, and the evolution characteristic contour of the vertical displace- ment in the $X O Z$ cutting plane of the extraction structure are shown in Figure 12. The red area in the contour is the area with larger displacement along the positive directions of $z$ -axis, and the blue area in the contour is the area with larger displacement along the negative directions of $z$-axis.

The extraction structure is formed after excavating ore loading roadways, ore drawing roadways, and drawbells. It can be seen from Figures 11(a) and 12(a) that the roof of the drawbells subsides, and the subsidence value is $18.3 \mathrm{~mm}$. Slight floor heave occurs in the floor of ore loading roadways and 

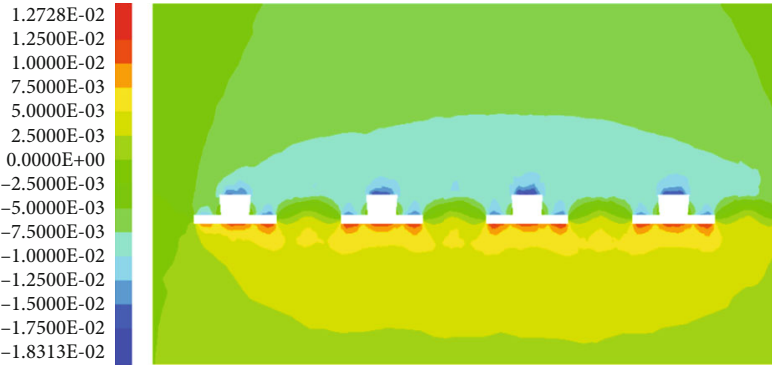

(a)

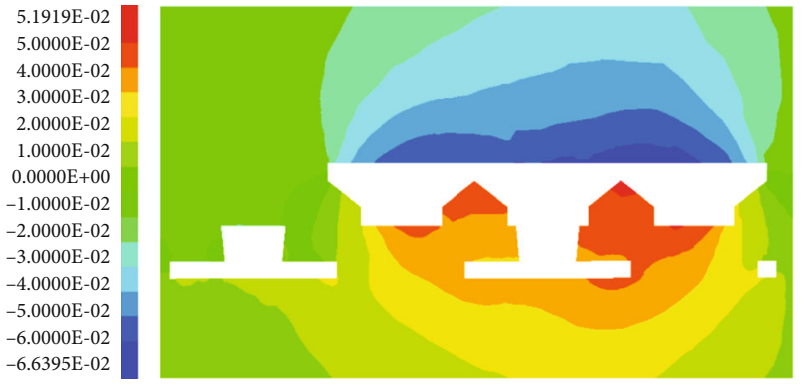

(c)

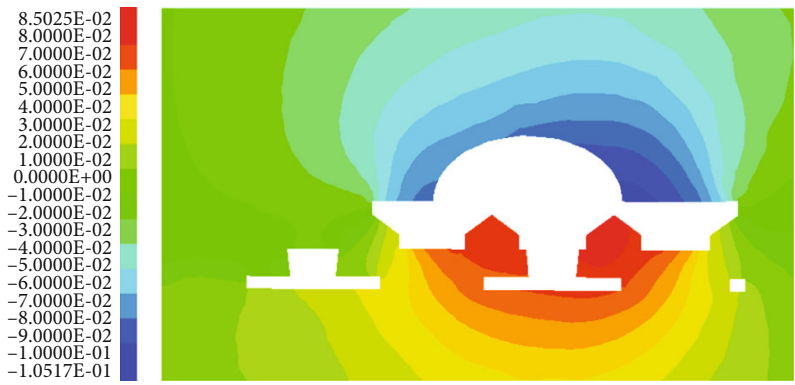

(e)

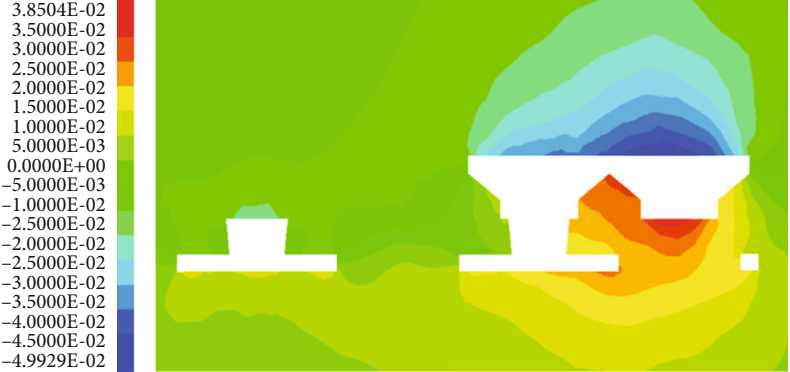

(b)
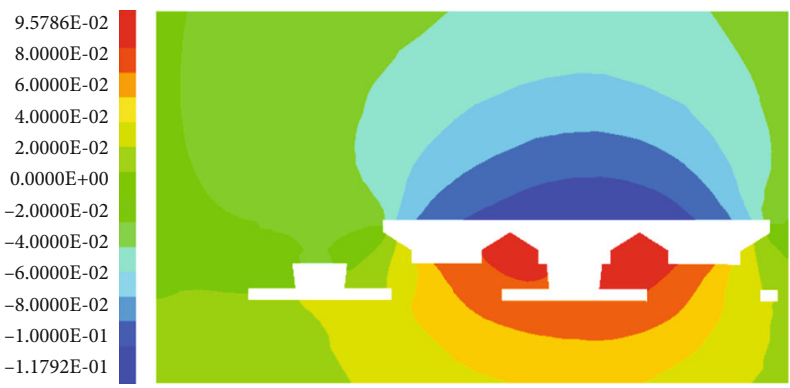

(d)
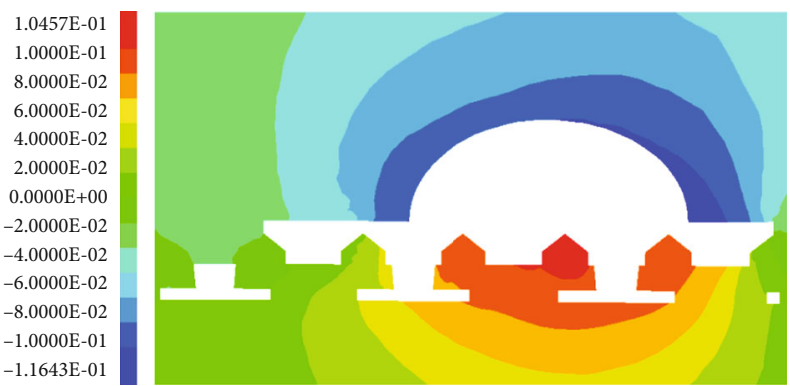

(f)

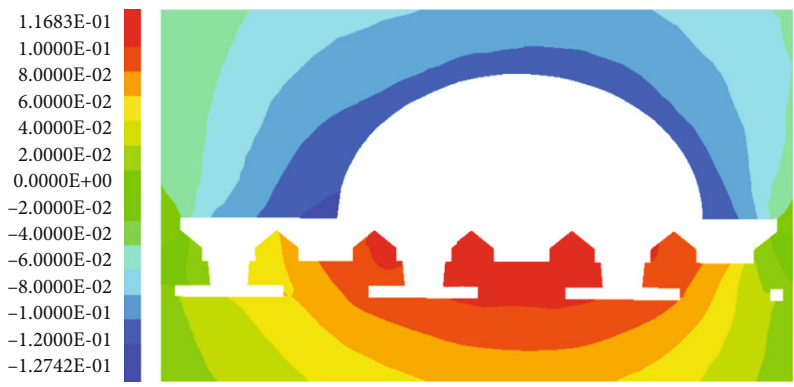

(g)

FIgURE 12: Evolution characteristic contour of the vertical displacement in the $X O Z$ cutting plane of the extraction structure: (a) after the formation of the extraction structure, (b) after excavation of the first undercut unit, (c) after excavation of the second undercut unit, (d) after excavation of the third undercut unit, (e) after initial caving, (f) after excavation of the fourth undercut unit and second caving unit, and $(\mathrm{g})$ after excavation of the fifth undercut unit and third caving unit.

drawbells, and the floor heave value is $12.7 \mathrm{~mm}$. The vertical displacement of other parts of the extraction structure is small, which does not affect the mining activities at all.

It can be seen from Figures 11(b)-11(d) and 12(b)-12(d) that, with the advancement of undercutting, the vertical displacement of the extraction structure under the undercut space increases with the increase of the undercutting area; after three steps of undercutting, the maximum vertical displacement of the floor of ore loading roadways, major apexes, and the floor of drawbells under the undercut space increases from $27.3 \mathrm{~mm}, 30.8 \mathrm{~mm}$, and $21.4 \mathrm{~mm}$ to $77.4 \mathrm{~mm}, 95.7 \mathrm{~mm}$, and $77.9 \mathrm{~mm}$, respectively.

It can be seen from Figures 11(d)-11(e) and 12(d)-12(e) that, after the overburden ore caving, the upward displacement of the extraction structure under the undercut space decreases slightly. However, it can be seen from Figures 11(e)-11(g) and $12(\mathrm{e})-12(\mathrm{~g})$ that, with the continuous increase of the undercut area, the upward displacement of the extraction 


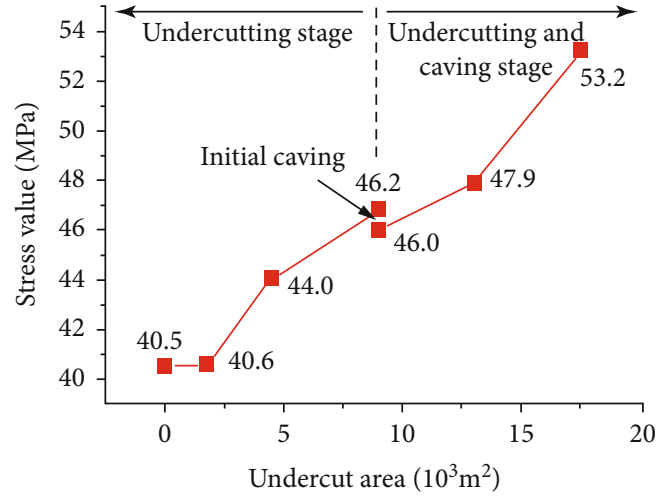

(a)

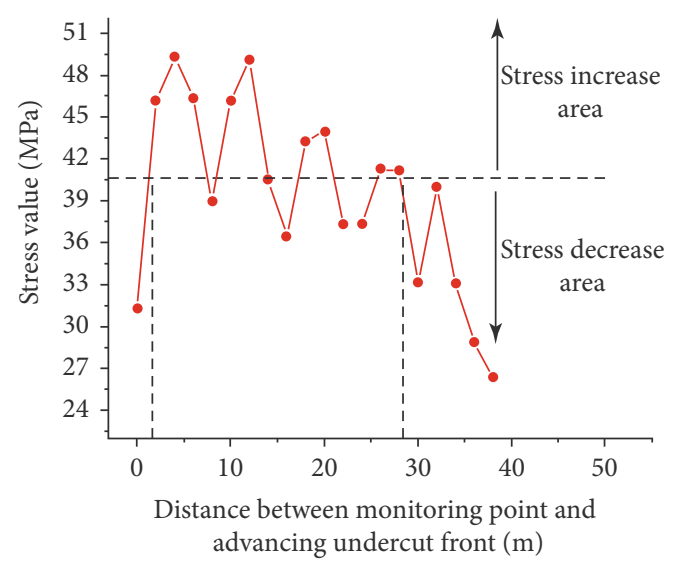

(b)

FIGURE 13: Variation law of compressive stress of the extraction structure near the advancing undercut: (a) variation law of maximum compressive stress with undercut area increasing and (b) spatial distribution of compressive stress near the advancing undercut.

structure under the undercut space increases continuously, the value of ore-loading roadways floor, major apexes, and drawbells floor under the undercut space increases to $102 \mathrm{~mm}, 98.5 \mathrm{~mm}$, and $117 \mathrm{~mm}$, respectively.

It can be seen from the comparison of Figures 9 and 12, with the advancing of undercutting, the horizontal displacement of the extraction structure near the advancing undercut front becomes larger, while the vertical displacement of the extraction structure under the undercut space becomes larger.

\section{Instability Mechanism of Extraction Structure in Whole Life Cycle}

5.1. Instability Mechanism of Extraction Structure near the Advancing Undercut Front. In order to study the instability mechanism of the extraction structure near the advancing undercut front, it is necessary to deeply analyze the stress and displacement variation laws of the extraction structure in the stage of undercutting and ore caving. According to the analysis of stress evolution characteristics of the extraction structure, the extraction structure is mainly affected by the compressive stress near the advancing undercut front. Therefore, the stress monitoring points were set at the production level near the advancing undercut front. The variation law of the maximum compressive stress with the undercut area is shown in Figure 13(a). Undercut area 0 in the figure represents the stress state of the extraction structure before undercutting.

According to the analysis in Figure 13(a), it can be found that before the initial caving of the overburden ore, with the continuous increase of the undercut area, the concentration degree of compressive stress in the production level near the advancing undercut front becomes more and more obvious. The main reason is that the stress arch is formed around the undercut space after undercutting. With the continuous increase of the undercut area, the span of the stress arch increases, and the weight of the overburden ore gradually increases; the degree of stress concentration in the range of stress arch becomes more and more high. It can be shown that the compressive stress of the extraction structure increases near the advancing undercut front. According to the Mohr-Coulomb criterion, if the shear failure condition of the rock mass with the extraction structure is reached, the ground pressure failure occurs. When the undercutting reaches the hydraulic radius of caving, the overburden ore produces initial caving, and the weight of overburden ore can be reduced. Therefore, the compressive stress in the range of the stress arch is reduced, which shows that the compressive stress of the extraction structure decreases slightly near the advancing undercut front. Thus, effective measures should be taken in time to induce the overburden ore caving after the undercutting, which can help to reduce the compressive stress concentration on the extraction structure near the advancing undercut front. After that, with the continuous undercutting, the stope span continued to increase; the weight of overburden ore borne by the stress arch increases continuously in general, although the process is accompanied by the collapse of ore. Therefore, the stress of the extraction structure near the advancing undercut front, and if the support is weak in production level, the ground pressure behavior become more and more intense. It can be shown as the ground pressure failure of ore loading roadways and ore drawing roadways.

In order to study the influence range of the stress arch near the advancing undercut front in the continuous caving stage, the stress monitoring points are arranged at the first ore loading roadway in front of the undercut front in the fifth undercut step. The spatial distribution of the compressive stress on the two sidewalls of the ore loading roadway near the advancing undercut front is shown in Figure 13(b). The highest compressive stress value of $40.6 \mathrm{MPa}$ after the formation of the extraction structure is taken as the baseline, and the stress of monitoring points higher than the baseline stress value are located in the stress increasing area, while the stress of monitoring points lower than the baseline stress value are located in the stress decreasing area. It can be seen from the analysis in Figure 13(b) that the position $2 \mathrm{~m} \sim 28 \mathrm{~m}$ in front of the advancing undercut front is in the affected range of the stress arch and in the stress increasing area. Therefore, 


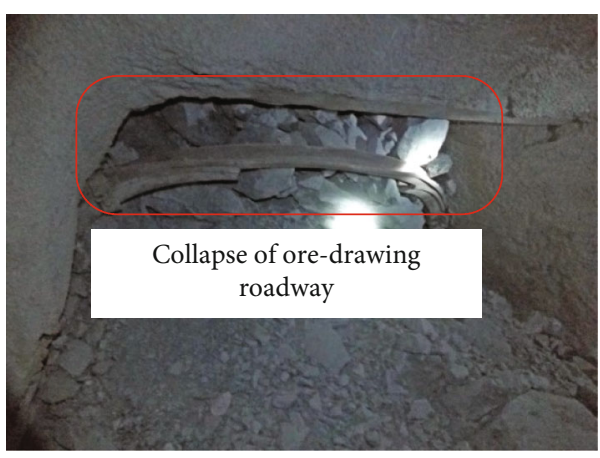

(a)

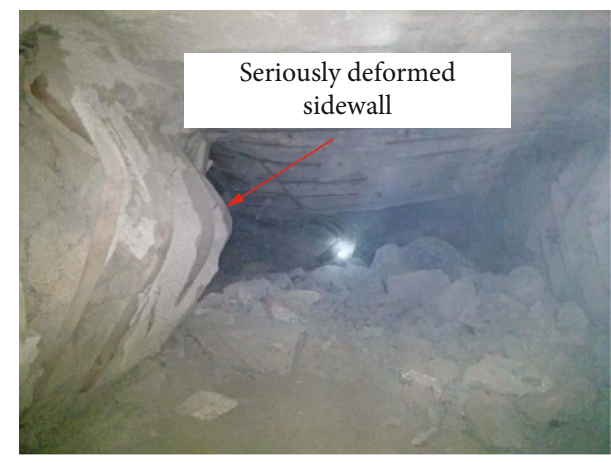

(b)

FIGURE 14: Instability characteristics of the extraction structure near the advancing undercut: (a) collapse of ore drawing roadway and (b) seriously deformed sidewall.

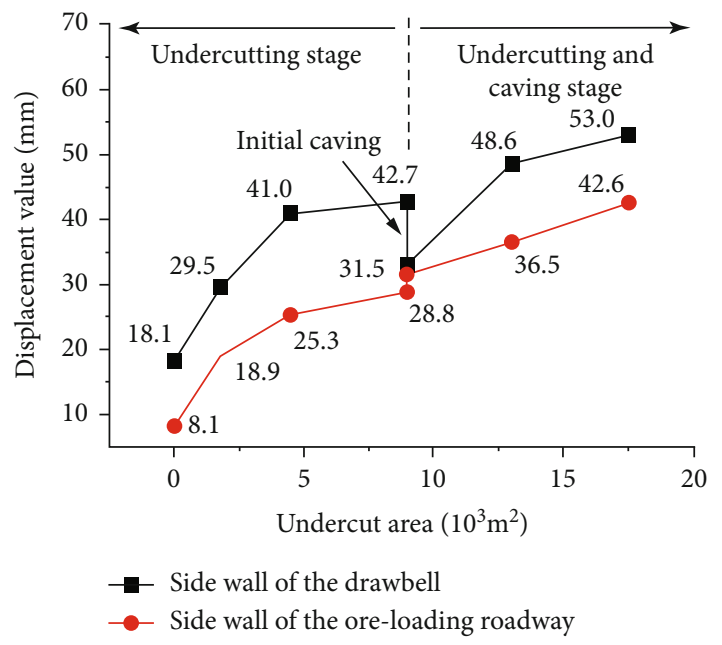

FIGURE 15: Variation law of maximum horizontal displacement with undercut area increasing.

during the process of undercutting, if the support of the extraction structure in front of advancing undercut front is weak or meets the extraction structure with low rock strength, the instability of extraction structure occurs. Therefore, the instability of the extraction structure can be found as early as $28 \mathrm{~m}$ in front of the advancing undercut front. The collapse of an ore drawing roadway is shown in Figure 14(a), and the seriously deformed sidewall of ore drawing through a vein is serious, as shown in Figure 14(b). The instability characteristics, occurrence time, and law of the extraction structure in front of the advancing undercut front are consistent with the numerical simulation results.

In order to study the deformation law of the extraction structure in front of the advancing undercut front, the displacement monitoring points are arranged at the production level. It is found that the horizontal displacement of the extraction structure in front of the advancing line is more obvious than the vertical displacement. The $x$-direction horizontal displacement analysis of the left sidewall of the ore drawing roadway and drawbell is shown in Figure 15.

It can be seen from Figure 15 that, with the increase of the undercut area, the displacement of the extraction structure in front of the advancing undercut front continues to increase and the deformation only decreases slightly after the initial caving. It shows that the collapse of the overburden ore as soon as possible is helpful to reduce the horizontal deformation of the extraction structure in front of the advancing undercut front. According to the field investigation, the sidewall deformation of the ore drawing in front of the advancing undercut front is serious, and it moves closer to the undercut space. As shown in Figure 14(b), the sidewall failure phenomenon is consistent with the numerical analysis results.

5.2. Instability Mechanism of Extraction Structure under Undercut Space. In order to study the instability mechanism of the extraction structure mechanism of the extraction structure under undercut space, it is necessary to deeply analyze the stress and displacement variation laws of the extraction structure in the stage of undercutting and ore caving. According to the analysis of stress evolution characteristics of the extraction structure, the extraction structure is mainly affected by the tensile stress under undercut space. Therefore, the stress monitoring points were set at the sidewalls of the ore loading roadway and the tip of major apex under undercut space. The variation law of the maximum tensile stress with the undercut area is shown in Figure 16(a). Undercut area 0 in the figure represents the stress state of the extraction structure before undercutting; no major apexes are formed at this time, so the tensile stress value of the major apex is missing.

It can be seen from the analysis in Figure 16(a) that, before the formation of the initial caving of the overburden ore, with the continuous increase of the undercut area, the tensile stress concentration degree of the sidewall of ore loading roadway and tip of the major apex under the undercut space becomes more and more obvious. It is mainly because of the combined action of high horizontal tectonic stress and vertical stress after undercutting that the extraction structure produces vertical upward bending deformation. In order to resist the bending deformation, the extraction structure produces higher tensile stress. After the initial caving of the overburden ore, the ore bulk falls on the extraction structure and begins to extract ores orderly. At this time, the tensile stress concentration on the sidewall of the ore loading roadway and tip of the major apex under the undercut space is 


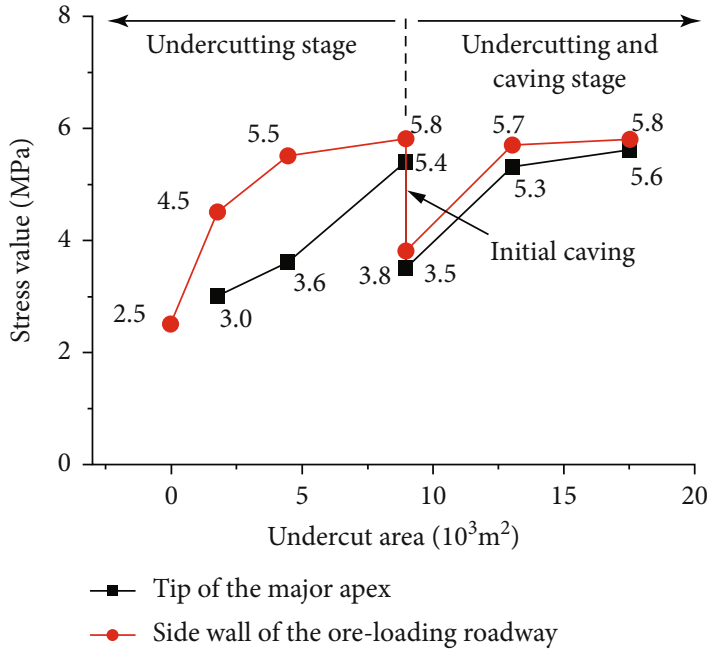

(a)

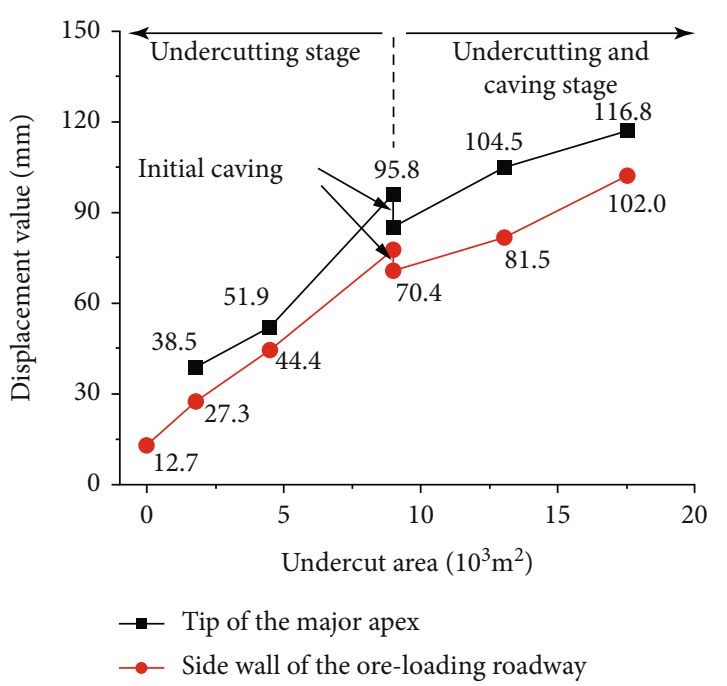

(b)

FIGURE 16: Stress and displacement evolution laws of extraction structure under undercut space: (a) variation law of maximum tensile stress with undercut area increasing and (b) variation law of maximum vertical displacement with undercut area increasing.

released to a certain extent. Measures should be taken to promote the collapse of the overburden ore in time after undercutting, which can effectively reduce the tensile stress concentration on the extraction structure under the undercut space. However, with the continuous increase of the undercut area and overburden ore caving, the stope space becomes larger and larger, and the bending deformation of the extraction structure becomes larger and larger, so the tensile stress concentration on the extraction structure continues to increase. At this time, if the stress exceeds the tensile strength of the rock mass of the extraction structure, the instability of the extraction structure occurs. The tensile stress on both sidewalls of the ore loading roadway under the undercut space is always higher than that on the tip of major apex, which indicates that the ore loading roadway is easier to be damaged than the major apex, and the support should be strengthened.

In order to study the deformation law of the extraction structure under the undercut space, the displacement monitoring points are arranged at the production level. It is found that the vertical displacement of the extraction structure under the undercut space is more obvious than the horizontal displacement. The upward displacement analysis of the floor of the ore drawing roadway and major apex is shown in Figure 16(b). With the increase of the undercut area, the vertical displacement of the extraction structure under the undercut space continues to increase, which shows that upward displacement of the ore drawing roadway floor and major apex increases. The deformation only decreases slightly after the initial caving, which indicates that the caving of the ore bulk and orderly ore drawing in the stope can help to reduce the vertical deformation of the extraction structure. Compared with Figures 16(a) and 16(b), it can be found that the tensile stress concentration on the extraction structure increases with the increase of the upward deflection of the extraction structure under the undercut space. It can be concluded that the tensile stress of the extraction structure under the undercut space is due to the resistance to the bending deformation of the extraction structure towards the undercut space. The upward deflection of the substructure is weakened after the initial caving, so the tensile stress concentration on the extraction structure is weakened, which helps to maintain the stability of the extraction structure. The rib spalling in the ore loading roadway is shown in Figure 17(a), and the floor heave in the ore loading roadway is shown in Figure 17(b); the results of the numerical analysis are consistent with the ground pressure failure phenomenon of field investigation.

\subsection{Repeated Instability Mechanism of Extraction Structure} in the Whole Life Cycle. In order to explore the mechanism of repeated instability of extraction structure in the whole life cycle, the stress variation law of the same position of the extraction structure with the undercut step is analyzed, as shown in Figure 18. Step 0 in Figure 18 is the state of the extraction structure when the undercutting is not carried out. After the first and second steps of undercutting, the monitoring point is located in the extraction structure in front of the advancing undercut front. After the third step of undercutting, the monitoring point is located in the extraction structure under the undercut space.

It can be seen from the analysis in Figure 18 that the maximum principal stress of the extraction structure in front of the advancing undercut front increases rapidly from $38.8 \mathrm{MPa}$ to $43.3 \mathrm{MPa}$ when the advancing undercut front is close to the monitoring point, and the sign is negative, so the extraction structure in front of the advancing undercut front is in the concentration area of compressive stress at this time. After the third step of undercutting, the extraction structure of the monitoring point is under the undercut space. At this time, the compressive stress gradually decreases to $5.2 \mathrm{MPa}$, while the minimum principal stress becomes positive and increases to $3.3 \mathrm{MPa}$, and the monitoring point of the extraction structure is in the tensile stress concentration area at this time. It 


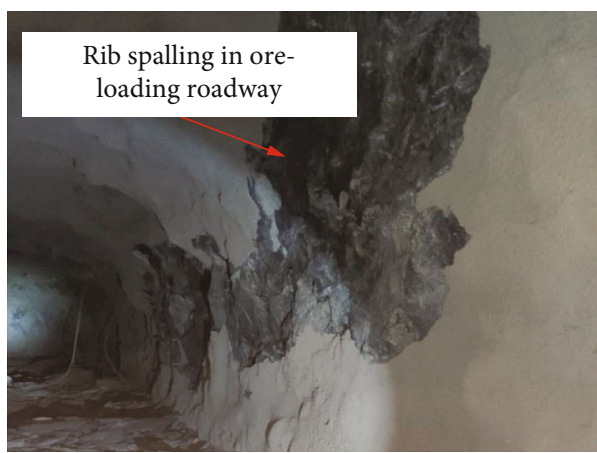

(a)

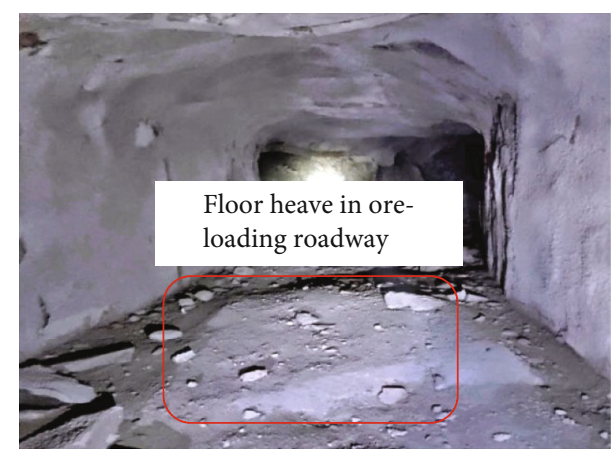

(b)

FIGURE 17: Instability characteristics of extraction structure under undercut space: (a) rib spalling in the ore loading roadway, (b) floor heave in the ore loading roadway (Figure 17 is reproduced from [19]).

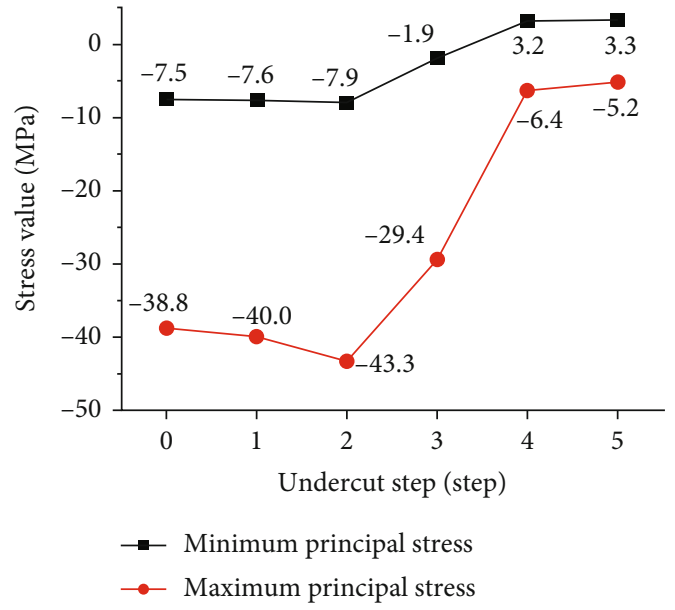

FIGURE 18: Stress variation law of extraction structure at the same position.

can be seen that the extraction structure in front of the advancing undercut front mainly presents compressive stress concentration, and the extraction structure under the undercut space mainly presents tensile stress concentration. With the gradual advancement of the undercutting, the extraction structure presents compressive stress concentration firstly and then tensile stress concentration at the same position. It is possible that the extraction structure can be damaged twice. As shown in Figure 19, the ore loading roadway is damaged again after the support.

In conclusion, the instability mechanism of the extraction structure in the whole life cycle in the block caving mine is summarized as follows: During the process of block caving mining under high level tectonic stress, with the advancement of undercutting, the stress of extraction structure presents the stress variation law that compressive stress concentration is prior to the tensile stress concentration. The schematic diagram of the instability mechanism of the extraction structure is shown in Figure 20. The stress arch is formed around the undercut space after undercutting; the spatial form presents as an egg-shaped thick wall structure with the long axis in the direction of the undercut advance and the short axis along the direction of the undercut front,

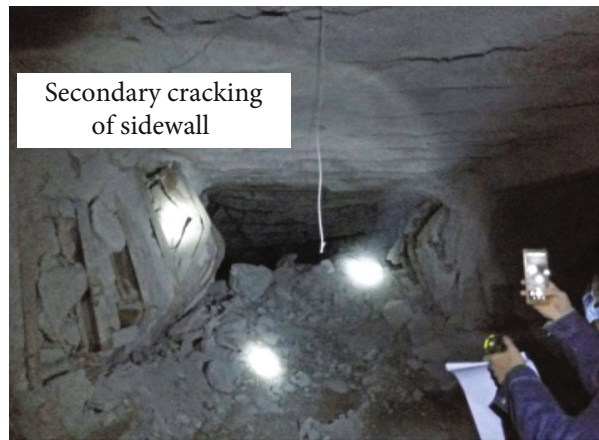

Figure 19: Secondary ground pressure damage of ore-loading roadway after supporting.

and the stope is surrounded by an egg-shaped thick wall structure. The extraction structure in front of the advancing undercut front is under the influence of the compressive stress increasing area, and the extraction structure under the undercut space is in the compressive stress unloading area and the tension stress increasing area. With the continuous increase of undercutting area and stope span, the weight of overburden ore borne by stress arch above undercut space is increasing, and the compressive stress of the extraction structure in front of the advancing undercut front increases continuously. According to the Mohr-Coulomb criterion, when the stress reaches the shear failure condition of the rock mass of the extraction structure, the ground pressure damage occurs, and the instability of the extraction structure can be caused with the increase of the damage range. As the undercutting continues, the extraction structure located on compression stress concentration area is gradually transferred to the position under the undercut space. Affected by the higher horizontal tectonic stress and vertical stress, the excavation space is squeezed, and the extraction structure produces upward bending deformation. In order to resist the bending deformation, the extraction structure gradually changes to the tension state. With the increasing of the undercut space, the concentration degree of tensile stress becomes higher and higher. When the tensile stress of the extraction structure exceeds the tensile strength of the rock mass, the ground pressure damage occurs again. Therefore, 


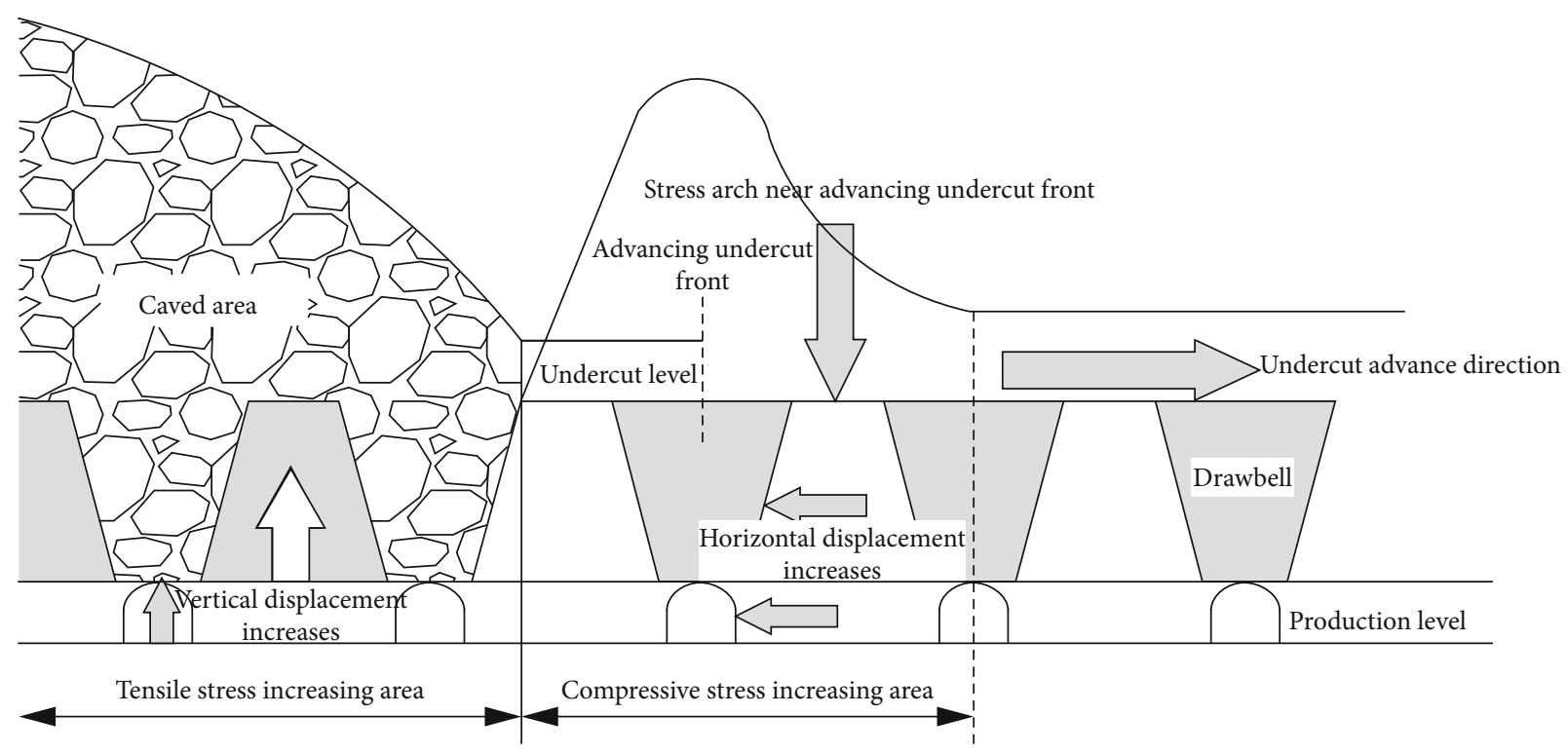

FIGURE 20: Schematic diagram of instability mechanism of extraction structure.

during the process of mine production, repeated instability of extraction structure may occur. With the increase of undercut area, the stress value increases gradually, and the ground pressure behavior becomes intense. At the same time, in the early stage of undercutting, to induce the overburden ore caving timely, orderly ore drawing can reduce the compressive stress concentration on the extraction structure in front of the advancing undercut front and the tensile stress concentration on the extraction structure under the undercut space. A combined support form of bolt mesh cable shotcreting and floor concrete reverse arch should be established before the high stress formation in front of advancing undercut front, which could effectively control the loose deformation of the surrounding rock of the ore drawing roadway, and increase the stability of the extraction structure.

\section{Conclusions}

The three-dimensional numerical model of the extraction structure in the whole life cycle in the block caving method was established; the stress and displacement evolution laws obtained are consistent with the instability characteristics of the extraction structure in mine site. The following conclusions can be drawn:

(1) The extraction structure near the advancing undercut front is prone to produce compressive stress concentration under the action of the surrounding rock stress arch in the stope; if the rock mass shear failure condition is reached, the instability of the extraction structure occurs

(2) The extraction structure near the advancing undercut front is gradually transferred to the area under the undercut space with undercut increase, and the tensile stress concentration gradually appears in the sidewall of ore-loading roadway and the tip of major apex; if the tensile strength of rock mass in extraction structure is exceeded, the instability occurs again

(3) To induce the overburden ore caving as soon as possible can reduce the compressive stress concentration on the extraction structure in front of the advancing undercut front and the tensile stress concentration on the extraction structure under the undercut space, which is helpful to reduce the probability of the instability of the extraction structure

\section{Data Availability}

The data used to support the findings of this study are available from the corresponding author upon request.

\section{Conflicts of Interest}

The authors declare that they have no conflicts of interest.

\section{Acknowledgments}

This research was supported by the National Natural Science Foundation of China (Grant No. 51574015).

\section{References}

[1] K.-S. Woo, E. Eberhardt, D. Elmo, and D. Stead, "Empirical investigation and characterization of surface subsidence related to block cave mining," International Journal of Rock Mechanics and Mining Sciences, vol. 61, pp. 31-42, 2013.

[2] J. P. Hurtado, N. Díaz, E. I. Acuña, and J. Fernández, "Shock losses characterization of ventilation circuits for block caving production levels," Tunnelling and Underground Space Technology, vol. 41, pp. 88-94, 2014.

[3] R. Trueman, R. L. Castro, and A. Halim, "Study of multiple draw-zone interaction in block caving mines by means of a 
large 3D physical model," International Journal of Rock Mechanics and Mining Sciences, vol. 45, no. 7, pp. 10441051, 2008.

[4] V. Sánchez, R. L. Castro, and S. Palma, "Gravity flow characterization of fine granular material for block caving," International Journal of Rock Mechanics and Mining Sciences, vol. 114, pp. 24-32, 2019.

[5] R. Rafiee, M. Ataei, R. KhalooKakaie, S. E. Jalali, F. Sereshki, and M. Noroozi, "Numerical modeling of influence parameters in cavabililty of rock mass in block caving mines," International Journal of Rock Mechanics and Mining Sciences, vol. 105, pp. 22-27, 2018.

[6] R. Trueman, M. Pierce, and R. Wattimena, "Quantifying stresses and support requirements in the undercut and production level drifts of block and panel caving mines," International Journal of Rock Mechanics and Mining Sciences., vol. 39, no. 5, pp. 617-632, 2002.

[7] R. J. Butcher, "Design rules for avoiding draw horizon damage in deep level block caves," Journal of the Southern African Institute of Mining and Metallurgy, vol. 99, no. 2, pp. 151155, 1999.

[8] P. J. Bartlett, Planning, Implementation, Operation and Monitoring of a Cave Mining Method with Coarse Fragmentation with Reference to Cave Mining at Premier, University of Pretoria, 1998.

[9] E. Rojas, R. Molina, A. Bonani, and H. Constanzo, "The preundercut caving method at the El Teniente mine, Codelco Chile," in Massmin 2000 Proceedings, vol. 29, pp. 261-266, Brisbane, Australia, 2000.

[10] G. V. Fernandes, K. Bosman, D. Angus, W. de Beer, and T. Urbancic, "Mapping cave front growth utilising the collective behaviour of seismicity and velocity fields," in Caving 2018, Fourth International Symposium on Block and Sublevel Caving, pp. 577-588, Vancouver, Canada, October, 2018.

[11] M. Pierce, "Forecasting vulnerability of deep extraction level excavations to draw-induced cave loads," Journal of Rock Mechanics and Geotechnical Engineering, vol. 11, no. 3, pp. 527-534, 2019.

[12] H. Sahupala, C. Brannon, S. Annavarapu, and K. Osborne, "Recovery of extraction pillars in the deep ore zone (DOZ) block cave, PT freeport Indonesia," in Massmin 2008, 5th International Conference \& Exhibition on Mass Mining, pp. 191-202, Lulea, Sweden, 2008.

[13] M. Orellana, C. Cifuentes, and J. Díaz, "Caving experiences in Esmeralda sector, El Teniente mine," in 3rd International Symposium on Block and Sublevel Caving, pp. 78-90, Santiago, Chile, June 2014.

[14] R. Castro, R. Gómez, M. Pierce, and J. Canales, “Experimental quantification of vertical stresses during gravity flow in block caving," International Journal of Rock Mechanics and Mining Sciences, vol. 127, p. 104237, 2020.

[15] R. Castro, Study of the Mechanisms of Gravity Flow for Block Caving, The University of Queensland, 2006.

[16] Z. Xia, Z. Tan, and Y. Miao, "Damage evolution mechanism of extraction structure during mining gently dipped orebody by block caving method," Geotechnical and Geological Engineering, vol. 38, no. 4, pp. 3891-3902, 2020.

[17] Z. Xia, Z. Tan, Q. Pei, and J. Wang, "Ground pressure damage evolution mechanism of extraction level excavations induced by poor undercutting in block caving method," Geotechnical and Geological Engineering, vol. 37, no. 5, pp. 4461-4472, 2019.
[18] Z. Xia and Z. Tan, "Study on instability mechanism of extraction structure under undercut space based on thin plate theory in block caving method," Shock and Vibration, vol. 2021, no. 2, Article ID 5548213, p. 11, 2021.

[19] Y. Zhang, Y. Jiang, D. Asahina, and C. Wang, "Experimental and numerical investigation on shear failure behavior of rock-like samples containing multiple non-persistent joints," Rock Mechanics and Rock Engineering, vol. 53, no. 10, pp. 4717-4744, 2020.

[20] C. Wu, J. Chu, S. Wu, and Y. Hong, "3D characterization of microbially induced carbonate precipitation in rock fracture and the resulted permeability reduction," Engineering Geology, vol. 249, pp. 23-30, 2019.

[21] C. Wu, J. Chu, S. Wu, L. Cheng, and L. A. van Paassen, "Microbially induced calcite precipitation along a circular flow channel under a constant flow condition," Acta Geotechnica, vol. 14, no. 3, pp. 673-683, 2019. 